\title{
Drug repurposing of metformin for Alzheimer's disease: Combining causal inference in medical records data and systems pharmacology for biomarker identification
}

Marie-Laure Charpignon ${ }^{1 *}$, Bella Vakulenko-Lagun ${ }^{2 *}$, Bang Zheng ${ }^{3 *}$, Colin Magdamo ${ }^{4}$, Bowen Su 5, Kyle Evans ${ }^{4,6}$, Steve Rodriguez ${ }^{4,6}$, Artem Sokolov ${ }^{6}$, Sarah Boswell $^{6}$, Yi-Han Sheu ${ }^{7}$, Melek Somai ${ }^{8}$, Lefkos Middleton ${ }^{3}$, Bradley T. Hyman ${ }^{4}$, Rebecca A. Betensky ${ }^{9}$, Stan N. Finkelstein $^{1}$, Roy E. Welsch $^{1,10}$, Ioanna Tzoulaki ${ }^{5,11,12 \#, \text { Deborah Blacker }}{ }^{7,13}$, Sudeshna Das ${ }^{4}$, and Mark W. Albers $^{4,6} \#^{\wedge}$

${ }^{1}$ Institute for Data, Systems, and Society, Massachusetts Institute of Technology, Cambridge, MA, USA

${ }^{2}$ Department of Statistics, University of Haifa, Mt Carmel, Haifa, Israel

${ }^{3}$ Ageing Epidemiology Research Unit, School of Public Health, Imperial College London, London, UK

${ }^{4}$ Department of Neurology, Massachusetts General Hospital / Harvard Medical School, Boston, MA, USA

${ }^{5}$ Department of Epidemiology and Biostatistics, School of Public Health, Imperial College London, London, UK

${ }^{6}$ Laboratory of Systems Pharmacology, Harvard Program in Therapeutic Science, Harvard Medical School, Boston, MA, USA

${ }^{7}$ Department of Psychiatry, Massachusetts General Hospital/Harvard Medical School, Boston, MA, USA

${ }^{8}$ Inception Labs, Collaborative for Health Delivery Sciences, Medical College of Wisconsin, Wauwatosa, WI, USA

${ }^{9}$ Department of Biostatistics, School of Global Public Health, New York University, New York, NY, USA

${ }^{10}$ Sloan School of Management, Massachusetts Institute of Technology, Cambridge, MA, USA

${ }^{11}$ Dementia Research Institute, Imperial College London, London, UK

${ }^{12}$ Deparment of Hygiene and Epidemiology, University of Ioannina, Ioannina, Greece

${ }^{13}$ Department of Epidemiology, Harvard T.H. Chan School of Public Health, Boston, MA, USA

* Contributed equally, and listed in alphabetical order \# Corresponding authors

$\wedge$ Contact author with Journal 
medRxiv preprint doi: https://doi.org/10.1101/2021.08.10.21261747; this version posted August 12, 2021. The copyright holder for this preprint (which was not certified by peer review) is the author/funder, who has granted medRxiv a license to display the preprint in perpetuity.

It is made available under a CC-BY-ND 4.0 International license .

\begin{abstract}
Metformin, an antidiabetic drug, triggers anti-aging cellular responses. Aging is the principal risk factor for dementia, but previous observational studies of the diabetes drugs metformin vs. sulfonylureas have been mixed. We tested the hypotheses that metformin improves survival and reduces the risk of dementia, relative to the sulfonylureas, by emulating target trials in electronic health records of diabetic patients at an academic-centered healthcare system in the US and a wide-ranging group of primary care practices in the UK. To address metformin's potentially dual influences on dementia risk - that it might reduce the hazard of death and put more people at risk of developing dementia while reducing the hazard of dementia by slowing biological aging, we used a competing risks approach and carefully grounded that within a causal inference emulated trial framework. To identify candidate biomarkers of metformin's actions in the brain that might mediate reduced dementia risk, we conducted an in-vitro systems pharmacology evaluation of metformin and glyburide on differentiated human neural cells through differential gene expression. We named our multi-dimensional approach DRIAD-EHR (Drug
\end{abstract} Repurposing in Alzheimer's Disease-Electronic Health Records). In intention-to-treat analyses, metformin was associated with a lower hazard of all-cause mortality than sulfonylureas in both cohorts. In competing risks analyses, there was also a lower cause-specific hazard of dementia onset among metformin initiators. In in-vitro studies, metformin reduced human neural cell expression of SPP1 and APOE, two secreted proteins that have been implicated in Alzheimer's disease pathogenesis and whose levels can be quantified in the CSF. Together, our findings suggest that metformin might prevent dementia in patients without type II diabetes. In addition, our results inform the design of clinical trials of metformin in nondiabetics and suggest a pharmacodynamic CSF biomarker, SPP1, for metformin's action in the brain.

\title{
INTRODUCTION
}

Repurposing drugs affords a route to therapeutic development that is shorter, less expensive, and more likely to succeed ${ }^{1}$. However, with fewer economic incentives for drug repurposing than for bringing new drugs to market, combined evidence from real-world data and mechanistic studies that supports the therapeutic hypothesis might justify a Randomized Clinical Trial (RCT). Alzheimer's disease (AD), with one to two decades of accumulating pathology prior to symptom onset, brings another challenge: a preclinical period so long that it is often not economically feasible for RCTs and presents ethical problems. Observational studies in Electronic Health Records (EHR) allow longer follow-up times than RCTs and offer the possibility of evaluating drugs already approved by the Food and Drug Administration (FDA) and/or the European Medicines Agency (EMA) within the preclinical period of dementia. Using the target trial method ${ }^{2,3}$ of conducting observational studies that aim to mimic RCTs, we 
medRxiv preprint doi: https://doi.org/10.1101/2021.08.10.21261747; this version posted August 12, 2021. The copyright holder for this preprint (which was not certified by peer review) is the author/funder, who has granted medRxiv a license to display the preprint in perpetuity.

It is made available under a CC-BY-ND 4.0 International license.

emulated the same target trial in two distinct EHR systems. We reasoned that replicating results across two samples from vastly different settings - one a healthcare system anchored in two large tertiary care hospitals and another a nation-wide primary care network-would provide a more robust estimate of the generalizability of the drug's effect ${ }^{4,5}$. Moreover, differences in medical practice, data collection, timing and length of follow-up, patterns of missingness, and known and unknown sources of bias between two EHR databases bolster any signal observed in both samples.

In this study, we emulated a target trial to estimate the effects of metformin compared to sulfonylureas on the risk of death and dementia. Metformin is a first-line antidiabetic drug with additional properties that may slow biological aging ${ }^{6,7}$, including some evidence of increased survival ${ }^{8}$. Since the risk of dementia rises very steeply with age ${ }^{9}$, it has been hypothesized that metformin would reduce such risk. Clinical studies of metformin, however, have had mixed results in older adults with incident dementia $^{10,11}$. To address the potentially opposing influences of metformin on dementia - that it might reduce the hazard of death and therefore put more people at risk of developing dementia while reducing the hazard of dementia by slowing biological aging, we used a competing risks analysis framework ${ }^{12}$. We used the target trial method ${ }^{2}$ to emulate a trial in the Research Patient Data Registry (US RPDR ${ }^{13}$ ) at Mass General Brigham (formerly Partners) Health Care system in the US and the UK Clinical Practice Research Datalink (UK CPRD ${ }^{14}$ ) database among initiators of metformin vs. the other first-line therapy for diabetes, the sulfonylureas (reference group).

In parallel, we conducted an in-vitro systems pharmacology evaluation of both drugs on differentiated human neural cells in culture to identify genes whose expression is differentially altered in neural cells with metformin treatment relative to the vehicle and to glyburide, one of the sulfonylureas. The secreted products from these differentially expressed genes are candidate pharmacodynamic markers of metformin's actions in the brain, which can be quantified in the cerebrospinal fluid (CSF). The goal of these emulated trials and in-vitro studies is to inform the design of clinical trials in cognitively healthy non-diabetics by enriching trials with participants most likely to benefit from metformin, based on the presence of demographic factors and central nervous system biomarkers linked to AD.

\section{RESULTS}

\section{Target trial emulation in the EHR from the US RPDR and UK CPRD}

We emulated the target trial in cohorts from the US RPDR and UK CPRD EHR databases (Table 1) with a one-year run-in period. Our target trial outcomes were time to first diagnosis of dementia or death in type II diabetics over age 50, starting on metformin- or sulfonylurea-monotherapy, and followed for at least one year. Of note, the one-year run-in period was selected to ensure sufficient drug exposure 
medRxiv preprint doi: https://doi.org/10.1101/2021.08.10.21261747; this version posted August 12, 2021. The copyright holder for this preprint (which was not certified by peer review) is the author/funder, who has granted medRxiv a license to display the preprint in perpetuity.

It is made available under a CC-BY-ND 4.0 International license .

before measuring outcomes. While the duration of a clinical trial is usually fixed, the duration of followup in the emulated trial is often much longer (US RPDR median: 5.0 years (max 12 years); UK CPRD median: 6.0 years (max 16 years)).

The US RPDR cohort, which was drawn from patients receiving primary care at an academic health care system, included 13,191 patients who started on metformin- $(11,229 ; 85 \%)$ or sulfonylureamonotherapy $(1,962 ; 15 \%)$ (Fig. 1a). Patients who had a diagnosis of dementia, or died within the first year of follow-up, were excluded from the study population to emulate the standard exclusion criterion in clinical trials of patients with baseline cognitive impairment or a high morbidity index. Additionally, patients with chronic kidney disease (CKD; see Extended Data Table 1 for definitions) at treatment initiation - a contraindication for metformin, but not for sulfonylureas-were excluded from the cohort. Metformin initiators were younger than their sulfonylurea counterparts (Table 2). Among the metformin initiators, there were more hypertensives and fewer missing values for baseline body mass index (BMI) than among the sulfonylurea initiators (Table 2). The baseline glycosylated hemoglobin (HbA1C) levels and other baseline characteristics, however, were comparable between the two groups (Table 2).

The UK CPRD cohort, which was drawn from primary care practices across 13 regions in the UK, included 108,025 patients in total with 94,208 (87\%) metformin initiators and 13,817 (13\%) sulfonylurea initiators (Fig. 1b). Patients who were diagnosed with dementia or died within the first year of follow-up were excluded from the study population (Fig. 1b). Those with CKD at treatment initiation (Extended Data Table 2) were also excluded. As in the US cohort, metformin initiators were younger than their sulfonylurea counterparts (Table 2). They were also more likely to have entered the cohort more recently and to have lower $\mathrm{HbA1C}$ and higher BMI at baseline. Further, they included more cardiovascular disease (CVD) and hypertension cases, but fewer cancer cases at baseline than the sulfonylurea group (Table 2).

\section{Metformin improved survival relative to the sulfonylureas in the US and UK cohorts}

First, we compared the effect of metformin vs. sulfonylureas on all-cause mortality in both cohorts, since metformin use has previously been reported to improve survival relative to the sulfonylureas in distinct $\mathrm{US}^{15}$ and $\mathrm{UK}^{16}$ cohorts of type II diabetics.

In the US RPDR cohort, $3.7 \%(n=415)$ of metformin initiators and $7.8 \%(n=154)$ of sulfonylurea initiators died during follow-up (median: 5.0 years; total: 74,107 person-years; range of age at death: 57104 years). Using a Cox Proportional Hazards (PH) regression model with Inverse Probability of Treatment Weighting (IPTW) to emulate randomization, the estimated hazard ratio for all-cause mortality was 0.57 (95\% CI: [0.48;0.67]) for metformin initiators relative to sulfonylurea initiators (Fig. 2a). Next, we examined metformin's effects by age ( $\leq 70$ vs. $>70$ ), sex, and BMI strata. Overall, there was no 
medRxiv preprint doi: https://doi.org/10.1101/2021.08.10.21261747; this version posted August 12, 2021. The copyright holder for this preprint (which was not certified by peer review) is the author/funder, who has granted medRxiv a license to display the preprint in perpetuity.

It is made available under a CC-BY-ND 4.0 International license .

evidence for heterogenous treatment effects across baseline age, sex, or BMI levels in the US RPDR cohort (Fig. 2b). Similar results were obtained using age strata defined as $\leq 65$ vs. $>65$ and $\leq 75$ vs. $>75$ (Extended Data Table 3).

In the larger UK CPRD cohort, $13.7 \%(n=12,941)$ of metformin initiators and $37.4 \%(n=5,173)$ of sulfonylurea initiators died during follow-up (median: 6.0 years; total: 696,725 person-years; range of age at death: 51-107 years). The UK CPRD had similar results for the effect of metformin vs. sulfonylureas on all-cause mortality in the full study population (Fig. 2c), with an overall hazard ratio of 0.66 (95\% CI: $0.61 ; 0.71)$. Results of subgroup analyses revealed evidence for a stronger effect of metformin among patients with a younger age at treatment initiation ( $\leq 70$ years), and patients with higher baseline BMI, but there was no difference by sex (Fig. 2d). The age-stratified analysis described above yielded similar results (Extended Data Table 4).

Our harmonized DRIAD-EHR approach — with analyses conducted in two very different patient populations and carefully adjusted for baseline differences in age and other risk factors - demonstrates a robust reduction in the hazard of death in patients treated with metformin compared to those treated with sulfonylureas, consistent with previous reports ${ }^{17,18}$. In both cohorts, we note that the survival curves between the two treatment groups separate approximately three years after treatment initiation, and that this separation persists for a long time (12 years observed in US RPDR and 16 in UK CPRD).

\section{Metformin reduced the hazard of dementia onset in the US and UK cohorts compared to sulfonylureas, but the risk differences between the drugs over time were clinically negligible}

Death is a competing event that precludes the development of dementia, but the use of a competing risks analysis in previous studies ${ }^{8,16}$ has been limited: death has been considered as a competing event for dementia only in a proportional hazards model where the hazard ratio is the measure of treatment effect. Here, we emulated a target trial of metformin vs. sulfonylureas in cognitively asymptomatic type II diabetics, estimating both the time-invariant hazard ratio and the time-dependent cumulative incidence function (CIF) for dementia, using a causal competing risks framework. We defined the average treatment effect (ATE) as the difference between risk functions corresponding to two potential outcomes (for definitions, see Methods).

In the US RPDR cohort, 7.7\% ( $\mathrm{n}=869)$ of metformin initiators and $12.3 \%(\mathrm{n}=241)$ of sulfonylurea initiators were diagnosed with dementia during follow-up (median: 5.0 years; total: 71,191 person-years; range of dementia onset age: 57-113 years). In a cause-specific Cox PH regression model with IPTW for emulation of baseline randomization, the estimated cause-specific hazard ratio for dementia was 0.81 (95\% CI: [0.69;0.94]) for metformin initiators relative to sulfonylurea initiators (Fig. 3a). In the UK CPRD cohort, $5.9 \%(n=5,561)$ of metformin initiators and $12.3 \%(n=1,699)$ of sulfonylurea initiators 
medRxiv preprint doi: https://doi.org/10.1101/2021.08.10.21261747; this version posted August 12, 2021. The copyright holder for this preprint (which was not certified by peer review) is the author/funder, who has granted medRxiv a license to display the preprint in perpetuity.

It is made available under a CC-BY-ND 4.0 International license.

were diagnosed with dementia during follow-up (median: 6.0 years; total: 695,281 person-years; range of dementia onset age: 51-114 years). The estimated cause-specific hazard ratio for dementia was 0.86 (95\% CI: $[0.77 ; 0.96])$ for metformin initiators, relative to sulfonylurea initiators (Fig. 3b), very similar to the US RPDR cohort.

In the time-dependent CIF analysis, the five-year risk (for definition, see Methods) of developing dementia in the US RPDR cohort was 7.2\% (95\% CI: [6.7;7.8]\%) among metformin initiators and 8.8\% (95\% CI: $[7.5 ; 10] \%)$ among sulfonylurea initiators, yielding a risk difference (for definition, see Methods) of $-1.6 \%$ (95\% CI: [-3.1;-0.17]\%) (Figs. 4a,c). In the UK CPRD cohort, the five-year risk difference was smaller at $-0.35 \%$ (95\% CI: [-0.68;-0.031]\%) (Figs. 4b,d). Although the hazard ratios for dementia in the UK CPRD and US RPDR were similar, the risk differences over time for both death and dementia were strikingly dissimilar in the two cohorts (Fig. 4).

First, while the dementia risk difference between metformin and sulfonylureas was minimal in the US RPDR, it always showed a slight benefit for metformin over sulfonylureas in this cohort. However, the risk difference observed in the UK CPRD changed over time, and the point of no risk difference between the two drugs was reached at about 7.5 years (Fig. 4). The seemingly discordant hazards ratio and CIF results in the UK CPRD sample are likely because metformin has a protective effect on both the hazard of dementia (HR=0.86, 95\% CI: $[0.77 ; 0.96])$ and the hazard of competing death $(\mathrm{HR}=0.64,95 \%$ CI: [0.59;0.69]), yielding more "survivors" over time in the metformin group, and thus more individuals at risk of developing dementia.

Second, the risk differences for both death and dementia were much closer to each other in the US RPDR than in the UK CPRD cohort. These differences between the two cohorts could potentially be explained by different population structures, particularly their baseline age distribution (Extended Data Fig. 1). The UK CPRD cohort had a higher death rate than the US RPDR one, affecting the total number of patients at risk over time (Extended Data Fig. 2). The comparison of the absolute cumulative hazards of dementia and death in a competing risks approach revealed additional differences between the UK CPRD and US RPRD cohorts, in terms of both the magnitude and trajectory of diagnosed dementia (Extended Data Fig. 3). In the US RPDR cohort, the rates of diagnosed dementia in both treatment arms were higher than the death rates, whereas the opposite pattern was observed in the UK CPRD. These underlying differences likely explain the differing risk curves for death and dementia between the two cohorts.

Overall, the benefits of metformin observed here can be interpreted in terms of both delaying dementia onset (Fig. 4, blue curves) and prolongating life without dementia (Fig. 4, orange curves). Notably, the risk difference for death was of larger magnitude in the UK CPRD than in the US RPDR cohort (respectively, a 10\% vs. 5\% reduction in risk after an average of 12 years of follow-up, Figs. 4c-d). 
medRxiv preprint doi: https://doi.org/10.1101/2021.08.10.21261747; this version posted August 12, 2021. The copyright holder for this preprint (which was not certified by peer review) is the author/funder, who has granted medRxiv a license to display the preprint in perpetuity.

It is made available under a CC-BY-ND 4.0 International license.

This was a result of a higher overall death rate in the UK CPRD cohort, relative to the rate of dementia onset. Conversely, in the US RPDR cohort, the overall rate of death was lower than the rate of dementia onset (Extended Data Fig. 3).

To assess the robustness of our results to modeling choices, we conducted a sensitivity analysis by using a nonparametric approach, thereby relaxing the proportional hazards assumption. Of note, the PH assumption held for both cause-specific hazards in the US RPDR cohort, while there was evidence of a deviation from this assumption in the UK CPRD cohort in terms of the hazards of death. However, this deviation was not large enough to affect our conclusions (Extended Data Figs. 4,5).

\section{Average treatment effect on dementia onset was greater among patients aged $<=70$ in the US RPDR}

Since age is the principal risk factor for dementia, we further investigated the effect modification of metformin as compared to sulfonylureas by the age at treatment initiation. Stratifying the US RPDR cohort into two groups (age $\leq 70$ and age $>70$ ), we found that the ATE of metformin vs. sulfonylureas on dementia onset observed in the full sample was mainly driven by the younger stratum (Fig. 3a), i.e., treatment initiation at age $\leq 70(\mathrm{HR}=0.69,95 \% \mathrm{CI}$ : [0.54;0.88]). Conversely, the effect of metformin on dementia onset was reduced for patients who started antidiabetic treatment at age $>70(\mathrm{HR}=0.94,95 \% \mathrm{CI}$ : $[0.79 ; 1.13])$. However, there were fewer patients who started antidiabetic treatment at age $>70$ than earlier (38\% vs. 62\%) and the older stratum had a shorter length of follow-up (median: 4.1 vs. 5.6 years; total: 22,960 vs. 48,231 person-years). Nevertheless, the age-specific finding in the US RPDR cohort suggests that metformin may be especially beneficial for those who initiate treatment at a younger age.

The difference in treatment effect between age groups was less clear in the larger UK CPRD cohort, with a HR of 0.82 (95\% CI: [0.67;0.99]) in patients aged $\leq 70$, and of 0.88 (95\% CI: [0.77;0.99]) in those aged $>70$ (Fig. 3b). Similar results were obtained using the risk difference: a stronger effect of metformin on dementia onset was observed in the US RPDR cohort, as compared to the UK CPRD, in patients who initiated treatment before age 70 (Extended Data Fig. 6).

\section{Difference in post-treatment HbA1C levels was not clinically significant for metformin vs. sulfonylurea initiators}

Since baseline HbA1C levels did not modify the effect of metformin, we also explored whether the drug acted primarily by a better control of blood sugar. For this, we applied a repeated measures mixed effects model on all $\mathrm{HbA} 1 \mathrm{C}$ values recorded three months after treatment initiation and beyond. In the US RPDR cohort, 10,180 (77\%) patients had HbA1C data available: 8,794 (78\%) and 1,386 (71\%) among metformin and sulfonylurea initiators, respectively. Interestingly, we found that although the average level of HbA1C was lower ( $\mathrm{p}<0.00001)$ in metformin vs. sulfonylurea initiators, the effect size was not 
medRxiv preprint doi: https://doi.org/10.1101/2021.08.10.21261747; this version posted August 12, 2021. The copyright holder for this preprint (which was not certified by peer review) is the author/funder, who has granted medRxiv a license to display the preprint in perpetuity.

It is made available under a CC-BY-ND 4.0 International license .

clinically significant (95\% CI: [-0.2601;-0.1511], see Extended Data Table 5). This suggests that the putative effect of metformin on dementia risk is likely through mechanisms other than the control of blood sugar.

\section{Metformin reduced the expression of innate immune modulators and APOE levels in cultured human neural cells}

The actions of metformin in human neurons have not been characterized well, despite pharmacokinetic evidence that metformin achieves biologically active concentrations in the CSF ${ }^{19}$. For 24 and 72 hours, we treated cultured differentiated human neural cells comprised of neurons, glia, and oligodendrocyte ${ }^{20}$ with metformin and glyburide (one of the sulfonylureas). We used two biologically relevant concentrations, 10 and $40 \mu \mathrm{M}$, which approximate CSF and plasma concentrations ${ }^{19}$, respectively (Fig. 5a). Following deep RNA-sequencing, we identified differentially expressed genes that were significantly altered in a dose-dependent manner (Fig. 5b, Extended Data Fig. 7). After treatment exposure, genes with the largest change were different between the two drugs, with greater effect sizes seen for glyburide, relative to metformin, at 72 hours. Pathway analysis revealed that metformin-altered genes were enriched in pathways related to the extracellular matrix, whereas glyburide-altered genes were enriched in pathways related to cholesterol metabolism (Extended Data Table 6).

Next, we limited the analysis to elements of the human secretome, since they are measurable in the $\operatorname{CSF}^{21}$ (Fig. 5c, Extended Data Table 7). To reflect subacute drug-induced profiles, we considered the 72-hour timeframe. Osteopontin (SPP1) emerged as the secreted protein with the greatest reduction in RNA levels at 72 hours and the greatest change overall. Previous work reported elevated levels of osteopontin in the serum of aging individuals ${ }^{22}$ and in the CSF of AD patients, correlating with cognitive decline $^{22}$. Moreover, elevated levels of SPP1 in microglia were detected in AD mouse models and human brain $s^{23}$. By looking at gene expression profiles of postmortem brain specimens in the ROSMAP ${ }^{24}$ and Mt. Sinai brain bank ${ }^{25}$ cohorts, we observed that SPP1 levels were elevated in tissue from the frontal and temporal lobes of patients with AD, relative to age-matched controls (Fig. 5d). Finally, we observed that RNA levels of APOE in cultured human neural cells were significantly reduced by metformin treatment (Extended Data Table 6). Together, the reduced gene expression of an innate immune modulator and a genetically relevant protein by metformin in human neural cells suggest a mechanism to diminish aging in the brain and thereby contribute to the delayed onset of clinical symptoms of dementia in type II diabetic patients.

\section{DISCUSSION}


In this study, we emulated a target trial of metformin vs. sulfonylureas in type II diabetic patients in two distinct EHRs. Although the length of follow-up varies across patients and prescribing patterns change over time, the advantage of observational studies is the potential for much longer follow-up periods than RCTs. This increased length of follow-up is of special importance, since many dementia risk factors likely operate over a long period of time ${ }^{26,27}$. After balancing key baseline demographic variables in the metformin and sulfonylurea cohorts by IPTW, we conducted an intention-to-treat analysis with a one-year run-in in two patient populations drawn from vastly diverse settings. One cohort was from a healthcare system anchored in two large tertiary care hospitals in the US and another from a nation-wide primary care network in the UK. Despite differences in medical practice, data collection, timing and length of follow-up, patterns of missingness, and known and unknown sources of bias, we found consistent evidence of metformin's benefit for overall survival and for dementia onset, relative to sulfonylureas. While prior studies only estimated a cause-specific hazard ratio for the impact of treatment on risk of dementia, in the CIFs from our competing risk framework we were able to account for the treatment effect on both outcomes jointly. Relative to sulfonylurea initiators, metformin initiators had a reduced hazard of dementia onset in both cohorts. This study corroborates previous observational studies $^{10,11,17,18,28}$ on the benefits of metformin on dementia risk in type II diabetics. Our competing risks analysis also shows how the risk of dementia depends on the baseline mortality rate of the population, a potential explanation of the neutral ${ }^{10,29}$ or deleterious ${ }^{11}$ effect of metformin on dementia onset seen in some other studies. To our knowledge, this work is the first attempt to comprehensively address competing death in a study of metformin and dementia, with a rigorous causal framework harmonized across two EHR databases.

The risk difference offers a nuanced view over time that is not captured by the time-invariant HR metric, which was similar across the two cohorts. An additional value of this observational study for planning future clinical trials is that it explores the source of the signal in subpopulations defined by criteria that could readily be implemented as inclusion and exclusion criteria. Our age-stratified analysis indeed demonstrated that type II diabetic patients aged 70 or younger at treatment initiation benefited most from metformin's effect on cognitive health.

Further, our analysis of HbA1C over time in the US RPDR showed a clinically negligible benefit among metformin vs. sulfonylurea initiators, indicating that the mechanism for metformin's effects on dementia onset and survival is unlikely to be simply a byproduct of better diabetic control. Moreover, our in-vitro systems pharmacology analysis in cultured human neural cells treated with metformin and glyburide identified over 100 differentially expressed genes, particularly affecting signaling networks implicated in aging. The secreted protein SPP1 emerges as a candidate CSF biomarker for metformin's 
action in the central nervous system (CNS). SPP1 was elevated in the CSF of MCI and mild AD patients in two independent studies ${ }^{20,21}$. Further, greater levels of SPP1 correlated with cognitive decline in these patients $^{21}$. SPP1 also elevated in response to TREM 2 activation in microglia ${ }^{30}$ in brains with AD pathology ${ }^{23,31}$. Lowering SPP1 levels in the CNS may thus be a unique mechanism of neuroprotection by metformin. Clinical investigators may consider adding elevated levels of SPP1 in the CSF as inclusion criteria for a clinical trial of metformin in subjects with preclinical AD biomarkers.

There are many strengths in our DRIAD-EHR approach. First, in this observational study, our two samples were followed for up to 16 years. Given that the preclinical stages of dementia can last 20 years $^{32}$, this study is examining a therapeutically relevant timeframe which is not feasible in randomized clinical trials. Second, we harmonized our analyses in two distinct EHR databases. The concordance of the hazard ratio estimates for both the survival and dementia outcomes across these two distinct patient populations indicates robust signals ${ }^{4,5}$. Third, we developed and implemented a causal competing risks framework, to account for death prior to developing dementia. By analyzing the cumulative incidence of death and dementia in parallel in both cohorts, we found that the mortality rate within a given population could have a significant impact on the cumulative risk of dementia, suggesting that a 3-5 year mortality index should be included as a criterion in clinical trials evaluating the efficacy of metformin to prevent the onset of dementia. Fourth, in complementary mechanistic studies, we analyzed gene expression changes in relevant human neural cell types at drug concentrations commensurate with observed levels in the plasma and CSF.

Nevertheless, this study has several limitations. First, while we addressed many sources of confounding, there were likely others that were unavailable or inadequately measured. In particular, the level of education was systematically unavailable in either dataset, of concern since it is known to affect both the exposure and outcomes of interest in this study. Additionally, relevant lifestyle factors like diet and physical activity ${ }^{33}$ were unavailable. Furthermore, the strong effect of age, the changes in prescribing patterns of sulfonylureas and metformin over the observation period ${ }^{34,35}$, and the complex differences observed in age at baseline, length of follow-up, and calendar time across the two treatments raises the possibility of residual confounding. Beyond this, in EHR, data missingness is very often informative and can lead to biases in study results ${ }^{36-38}$. Second, the absence of linkage to claims data in the US RPDR cohort prevented us from verifying that patients were truly treatment initiators, or from verifying the length of exposure by confirming that prescriptions were filled and refilled at the expected rate. Third, since this study was an intention-to-treat analysis, it did not include potential add-on drugs incorporated later in the patient's clinical course or consider antidiabetic treatment switches. Thus, transition from monotherapy to a dual (or more) hypoglycemic regimen could be a possible source of confounding for both dementia and death outcomes. Fourth, this study might suffer from measurement errors in the 
primary outcome of interest ${ }^{39}$. Dementia is under-diagnosed and under-recorded, both in the $\mathrm{US}^{40}$ and $\mathrm{UK}^{41,42}$. Patients and their families may fail to mention symptoms to their primary care physicians and physicians might not routinely screen for cognitive health. Even when such symptoms are recognized and described directly or indirectly in physicians' notes, the relevant diagnostic code or prescription used here as a proxy for the disease might not be present ever-or may not appear until late in the course. In other cases, dementia might be overcoded ${ }^{43,44}$. Hence, in the future, we aim to deploy text mining and natural language processing techniques on clinical notes, radiologic image analysis, and other clinical data to better identify subjects with dementia and more precisely determine the timing of disease onset. Fifth, while our study was conducted in two different populations, both are primarily white and have access to health care. While the UK CPRD population is fairly representative of the UK population, the US RPDR population is limited to a single region, less diverse, and more advantaged than the US population as a whole. Sixth, in our mechanistic studies, we approximated chronic exposure to metformin and glyburide through relatively short durations, in cultured human neural cells that did not include all the cell types in the brain, including microglia. Besides, metformin might act by chronic changes in signaling networks in unrepresented cell types that were not evaluated in these studies.

Applying a causal competing risks framework to estimate the effects of metformin compared to sulfonylureas among type II diabetic patients showed consistent findings across two disparate datasets. These robust EHR findings were buttressed by in-vitro analyses of human neural cells at pharmacologically relevant concentrations that revealed novel actions of metformin, relative to glyburide and to its actions in other cell types. Together, this multi-dimensional DRIAD-EHR approach uncovered four pragmatic insights that can be incorporated into clinical trial design: first, an estimate of efficacy among asymptomatic individuals that is validated in two distinct databases; second, the importance of treating mortality as a competing risk for clinical trials that last three to five years; third, enrolling people aged less than 70 (or perhaps less than 75 in non-diabetics, among whom the onset of dementia is, on average, later); and fourth, a novel, mechanistically relevant CSF biomarker, SPP1, for recruitment into the clinical trial that can also serve as a pharmacodynamic mechanism of action. These clinical trials of metformin in cognitively intact non-diabetics will determine whether these promising results can be translated into future prevention strategies of dementia in a cost-effective manner.

\section{ACKNOWLEDGMENTS}

We thank Alexander Soukas, Victor Castro, and Peter K. Sorger for helpful discussions. The authors thank Shawn Murphy, Henry Chueh, and the Partners Health Care Research Patient Data Registry group for facilitating use of their database. This study is based in part on data from the Clinical Practice Research Datalink database obtained under license from the UK Medicines and Healthcare products 
medRxiv preprint doi: https://doi.org/10.1101/2021.08.10.21261747; this version posted August 12, 2021. The copyright holder for this preprint (which was not certified by peer review) is the author/funder, who has granted medRxiv a license to display the preprint in perpetuity.

It is made available under a CC-BY-ND 4.0 International license .

Regulatory Agency. However, the interpretation and conclusions contained in this article are those of the authors alone and not necessarily those of the NHS, the NIHR, or the Department of Health. The results published here are in part based on data obtained from the AMP-AD Knowledge Portal (doi:10.7303/syn2580853). These data were generated from postmortem brain tissue collected through the Mount Sinai VA Medical Center Brain Bank, led by Dr. Eric Schadt from Mount Sinai School of Medicine, by the Rush Alzheimer's Disease Center, Rush University Medical Center, Chicago, and by the following sources: The Mayo Clinic Alzheimer's Disease Genetic Studies, led by Dr. Nilufer Taner and Dr. Steven G. Younkin, Mayo Clinic, Jacksonville, FL using samples from the Mayo Clinic Study of Aging, the Mayo Clinic Alzheimer's Disease Research Center, and the Mayo Clinic Brain Bank. We thank the NIH R01 AG058063 (awarded to M.W.A), P30 AG062421 (awarded to B.T.H.), a CART grant (awarded to M.W.A.), an administrative supplement to U54 CA22508 (awarded to M.W.A.), IBM Research (awarded to R.E.W. and S.N.F.), the Abdul Latif Jameel Clinic for Machine Learning in Health grant (awarded to R.E.W. and S.N.F.), the UK Dementia Research Institute which receives its funding from UK DRI Ltd, funded by the UK Medical Research Council (awarded to I.T.), the Alzheimer's Society and Alzheimer's Research UK, support by the British Heart Foundation Centre for Research Excellence at Imperial College (awarded to I.T.), the Hellenic Foundation for Research and Innovation (HFRI) (awarded to I.T.), and the General Secretariat for Research and Technology (GSRT) (awarded to I.T.) for support.

\section{AUTHOR CONTRIBUTIONS}

I.T., D.B., S.D., and M.W.A. conceived of the study; M.L.C., B.V.L., C.M., and S.D. curated data and performed analyses on the RPDR EHR dataset; B.Z. and B.S. curated data and performed analyses on the CPRD EHR dataset; I.T. and L.M. supervised the CPRD EHR dataset analysis; M.L.C., B.V.L., B.Z., C.M., Y.-H.S., R.A.B., and S.D. conceived the analysis and wrote code for the competing risks analysis; K.E., S.R., A.S., and S.B. generated and analyzed data from the in-vitro systems pharmacology studies; M.L.C., B.Z., B.V.L., C.M., S.F., R.E.W., D.B., S.D., and M.W.A. wrote the first draft; and all authors revised the manuscript. S.N.F, R.E.W., and M.W.A. secured funding for the study.

\section{COMPETING INTERESTS}

The authors declare the following competing interests:

B.T.H. is a member of the SAB and owns shares in Dewpoint. He also serves on an advisory panel for Biogen, and his laboratory has current research funding from AbbVie. His wife is an employee and 
medRxiv preprint doi: https://doi.org/10.1101/2021.08.10.21261747; this version posted August 12, 2021. The copyright holder for this preprint (which was not certified by peer review) is the author/funder, who has granted medRxiv a license to display the preprint in perpetuity.

It is made available under a CC-BY-ND 4.0 International license .

shareholder of Novartis. R.A.B. serves on an advisory board for Biogen. M.W.A. is a consultant for

Transposon Rx and receives research support from IFF.

\section{REFERENCES}

$1 \quad$ Pushpakom, S. et al. Drug repurposing: progress, challenges and recommendations. Nature Reviews Drug Discovery 18, 41-58, doi:10.1038/nrd.2018.168 (2018).

2 Hernan, M. A. \& Robins, J. M. Using Big Data to Emulate a Target Trial When a Randomized Trial Is Not Available. Am J Epidemiol 183, 758-764, doi:10.1093/aje/kwv254 (2016).

3 Hernan, M. A., Brumback, B. \& Robins, J. M. Marginal structural models to estimate the causal effect of zidovudine on the survival of HIV-positive men. Epidemiology 11, 561570, doi:10.1097/00001648-200009000-00012 (2000).

4 Kohane, I. S. et al. What Every Reader Should Know About Studies Using Electronic Health Record Data but May be Afraid to Ask. J Med Internet Res, doi:10.2196/22219 (2021).

5 in Reproducibility and Replicability in Science (2019).

6 Barzilai, N., Crandall, J. P., Kritchevsky, S. B. \& Espeland, M. A. Metformin as a Tool to Target Aging. Cell Metab 23, 1060-1065, doi:10.1016/j.cmet.2016.05.011 (2016).

7 Kulkarni, A. S. et al. Metformin regulates metabolic and nonmetabolic pathways in skeletal muscle and subcutaneous adipose tissues of older adults. Aging Cell 17, doi:10.1111/acel.12723 (2018).

8 Campbell, J. M., Bellman, S. M., Stephenson, M. D. \& Lisy, K. Metformin reduces allcause mortality and diseases of ageing independent of its effect on diabetes control: A systematic review and meta-analysis. Ageing Res Rev 40, 31-44, doi:10.1016/j.arr.2017.08.003 (2017).

9 Hou, Y. et al. Ageing as a risk factor for neurodegenerative disease. Nat Rev Neurol 15, 565-581, doi:10.1038/s41582-019-0244-7 (2019).

10 Scherrer, J. F. et al. Association Between Metformin Initiation and Incident Dementia Among African American and White Veterans Health Administration Patients. Ann Fam Med 17, 352-362, doi:10.1370/afm.2415 (2019).

11 Imfeld, P., Bodmer, M., Jick, S. S. \& Meier, C. R. Metformin, other antidiabetic drugs, and risk of Alzheimer's disease: a population-based case-control study. J Am Geriatr Soc 60, 916-921, doi:10.1111/j.1532-5415.2012.03916.x (2012).

12 Andersen, P. K., Borgan, O., Gill, R. D. \& Keiding, N. Statistical Models Based on Counting Processes. (1993).

13 Nalichowski, R., Keogh, D., Chueh, H. C. \& Murphy, S. N. Calculating the benefits of a Research Patient Data Repository. AMIA Annu Symp Proc, 1044 (2006).

14 Herrett, E. et al. Data Resource Profile: Clinical Practice Research Datalink (CPRD). Int J Epidemiol 44, 827-836, doi:10.1093/ije/dyv098 (2015).

15 Marcum, Z. A. et al. Mortality Associated with Metformin Versus Sulfonylurea Initiation: A Cohort Study of Veterans with Diabetes and Chronic Kidney Disease. J Gen Intern Med 33, 155-165, doi:10.1007/s11606-017-4219-3 (2018).

16 Bannister, C. A. et al. Can people with type 2 diabetes live longer than those without? A comparison of mortality in people initiated with metformin or sulphonylurea 
medRxiv preprint doi: https://doi.org/10.1101/2021.08.10.21261747; this version posted August 12, 2021. The copyright holder for this preprint (which was not certified by peer review) is the author/funder, who has granted medRxiv a license to display the preprint in perpetuity. It is made available under a CC-BY-ND 4.0 International license .

monotherapy and matched, non-diabetic controls. Diabetes Obes Metab 16, 1165-1173, doi:10.1111/dom.12354 (2014).

17 Sluggett, J. K. et al. Metformin and Risk of Alzheimer's Disease Among CommunityDwelling People With Diabetes: A National Case-Control Study. J Clin Endocrinol Metab 105, doi:10.1210/clinem/dgz234 (2020).

18 Wium-Andersen, I. K., Osler, M., Jorgensen, M. B., Rungby, J. \& Wium-Andersen, M. $\mathrm{K}$. Antidiabetic medication and risk of dementia in patients with type 2 diabetes: a nested case-control study. Eur J Endocrinol 181, 499-507, doi:10.1530/EJE-19-0259 (2019).

19 Labuzek, K. et al. Quantification of metformin by the HPLC method in brain regions, cerebrospinal fluid and plasma of rats treated with lipopolysaccharide. Pharmacol Rep 62, 956-965, doi:10.1016/s1734-1140(10)70357-1 (2010).

20 Song, Y. et al. A dynamic view of the proteomic landscape during differentiation of ReNcell VM cells, an immortalized human neural progenitor line. Sci Data 6, 190016, doi:10.1038/sdata.2019.16 (2019).

21 Paterson, R. W. et al. A targeted proteomic multiplex CSF assay identifies increased malate dehydrogenase and other neurodegenerative biomarkers in individuals with Alzheimer's disease pathology. Transl Psychiatry 6, e952, doi:10.1038/tp.2016.194 (2016).

22 Comi, C. et al. Osteopontin is increased in the cerebrospinal fluid of patients with Alzheimer's disease and its levels correlate with cognitive decline. J Alzheimers Dis 19, 1143-1148, doi:10.3233/JAD-2010-1309 (2010).

23 Sala Frigerio, C. et al. The Major Risk Factors for Alzheimer's Disease: Age, Sex, and Genes Modulate the Microglia Response to Abeta Plaques. Cell Rep 27, 1293-1306 e1296, doi:10.1016/j.celrep.2019.03.099 (2019).

24 Bennett, D. A. et al. Religious Orders Study and Rush Memory and Aging Project. J Alzheimers Dis 64, S161-S189, doi:10.3233/JAD-179939 (2018).

25 Wang, M. et al. The Mount Sinai cohort of large-scale genomic, transcriptomic and proteomic data in Alzheimer's disease. Sci Data 5, 180185, doi:10.1038/sdata.2018.185 (2018).

26 Cummings, J., Lee, G., Ritter, A., Sabbagh, M. \& Zhong, K. Alzheimer's disease drug development pipeline: 2019. Alzheimers Dement (N Y) 5, 272-293, doi:10.1016/j.trci.2019.05.008 (2019).

27 Oxford, A. E., Stewart, E. S. \& Rohn, T. T. Clinical Trials in Alzheimer's Disease: A Hurdle in the Path of Remedy. Int J Alzheimers Dis 2020, 5380346, doi:10.1155/2020/5380346 (2020).

28 Orkaby, A. R., Cho, K., Cormack, J., Gagnon, D. R. \& Driver, J. A. Metformin vs sulfonylurea use and risk of dementia in US veterans aged $>/=65$ years with diabetes. Neurology 89, 1877-1885, doi:10.1212/WNL.0000000000004586 (2017).

29 Scherrer, J. F. et al. Metformin and Sulfonylurea Use and Risk of Incident Dementia. Mayo Clin Proc 94, 1444-1456, doi:10.1016/j.mayocp.2019.01.004 (2019).

30 Zhou, Y. et al. Human and mouse single-nucleus transcriptomics reveal TREM2dependent and TREM2-independent cellular responses in Alzheimer's disease. Nat Med 26, 131-142, doi:10.1038/s41591-019-0695-9 (2020).

31 Krasemann, S. et al. The TREM2-APOE Pathway Drives the Transcriptional Phenotype of Dysfunctional Microglia in Neurodegenerative Diseases. Immunity 47, 566-581 e569, doi:10.1016/j.immuni.2017.08.008 (2017). 
medRxiv preprint doi: https://doi.org/10.1101/2021.08.10.21261747; this version posted August 12, 2021. The copyright holder for this preprint (which was not certified by peer review) is the author/funder, who has granted medRxiv a license to display the preprint in perpetuity. It is made available under a CC-BY-ND 4.0 International license .

32 Jack, C. R., Jr. et al. NIA-AA Research Framework: Toward a biological definition of Alzheimer's disease. Alzheimers Dement 14, 535-562, doi:10.1016/j.jalz.2018.02.018 (2018).

33 Livingston, G. et al. Dementia prevention, intervention, and care: 2020 report of the Lancet Commission. Lancet 396, 413-446, doi:10.1016/S0140-6736(20)30367-6 (2020).

34 Wilkinson, S. et al. Changing use of antidiabetic drugs in the UK: trends in prescribing 2000-2017. BMJ Open 8, e022768, doi:10.1136/bmjopen-2018-022768 (2018).

35 Soukas, A. A., Hao, H. \& Wu, L. Metformin as Anti-Aging Therapy: Is It for Everyone? Trends Endocrinol Metab 30, 745-755, doi:10.1016/j.tem.2019.07.015 (2019).

36 Lin, K. J. et al. Identifying Patients With High Data Completeness to Improve Validity of Comparative Effectiveness Research in Electronic Health Records Data. Clin Pharmacol Ther 103, 899-905, doi:10.1002/cpt.861 (2018).

37 Haneuse, S. et al. Learning About Missing Data Mechanisms in Electronic Health Records-based Research: A Survey-based Approach. Epidemiology 27, 82-90, doi:10.1097/EDE.0000000000000393 (2016).

38 Haneuse, S. \& Daniels, M. A General Framework for Considering Selection Bias in EHR-Based Studies: What Data Are Observed and Why? EGEMS (Wash DC) 4, 1203, doi:10.13063/2327-9214.1203 (2016).

39 Wolters, F. J. et al. Twenty-seven-year time trends in dementia incidence in Europe and the United States: The Alzheimer Cohorts Consortium. Neurology 95, e519-e531, doi:10.1212/WNL.0000000000010022 (2020).

402020 Alzheimer's disease facts and figures. Alzheimers Dement, doi:10.1002/alz.12068 (2020).

41 Pujades-Rodriguez, M. et al. The diagnosis, burden and prognosis of dementia: A recordlinkage cohort study in England. PLoS One 13, e0199026, doi:10.1371/journal.pone.0199026 (2018).

42 Ford, E. et al. Identifying undetected dementia in UK primary care patients: a retrospective case-control study comparing machine-learning and standard epidemiological approaches. BMC Medical Informatics and Decision Making 19, 248, doi:10.1186/s12911-019-0991-9 (2019).

43 Ostbye, T., Taylor, D. H., Jr., Clipp, E. C., Scoyoc, L. V. \& Plassman, B. L. Identification of dementia: agreement among national survey data, medicare claims, and death certificates. Health Serv Res 43, 313-326, doi:10.1111/j.1475-6773.2007.00748.x (2008).

44 Chen, Y., Tysinger, B., Crimmins, E. \& Zissimopoulos, J. M. Analysis of dementia in the US population using Medicare claims: Insights from linked survey and administrative claims data. Alzheimers Dement (N Y) 5, 197-207, doi:10.1016/j.trci.2019.04.003 (2019).

45 Benchimol, E. I. et al. The REporting of studies Conducted using Observational Routinely-collected health Data (RECORD) statement. PLoS Med 12, e1001885, doi:10.1371/journal.pmed.1001885 (2015).

46 Imam, T. H. Changes in metformin use in chronic kidney disease. Clin Kidney J 10, 301304, doi:10.1093/ckj/sfx017 (2017).

47 VanderWeele, T. J. Principles of confounder selection. Eur J Epidemiol 34, 211-219, doi:10.1007/s10654-019-00494-6 (2019).

48 Lesko, C. R. \& Lau, B. Bias Due to Confounders for the Exposure-Competing Risk Relationship. Epidemiology 28, 20-27, doi:10.1097/EDE.0000000000000565 (2017). 
medRxiv preprint doi: https://doi.org/10.1101/2021.08.10.21261747; this version posted August 12, 2021. The copyright holder for this preprint (which was not certified by peer review) is the author/funder, who has granted medRxiv a license to display the preprint in perpetuity. It is made available under a CC-BY-ND 4.0 International license .

49 Brookhart, M. A. et al. Variable selection for propensity score models. Am J Epidemiol 163, 1149-1156, doi:10.1093/aje/kwj149 (2006).

50 Ding, P., VanderWeele, T. J. \& Robins, J. M. Instrumental variables as bias amplifiers with general outcome and confounding. Biometrika 104, 291-302, doi:10.1093/biomet/asx009 (2017).

51 Guerreiro, R. \& Bras, J. The age factor in Alzheimer's disease. Genome Med 7, 106, doi:10.1186/s13073-015-0232-5 (2015).

52 Chatterjee, S. et al. Type 2 Diabetes as a Risk Factor for Dementia in Women Compared With Men: A Pooled Analysis of 2.3 Million People Comprising More Than 100,000 Cases of Dementia. Diabetes Care 39, 300-307, doi:10.2337/dc15-1588 (2016).

53 Riedel, B. C., Thompson, P. M. \& Brinton, R. D. Age, APOE and sex: Triad of risk of Alzheimer's disease. J Steroid Biochem Mol Biol 160, 134-147, doi:10.1016/j.jsbmb.2016.03.012 (2016).

54 van der Flier, W. M. \& Scheltens, P. Epidemiology and risk factors of dementia. J Neurol Neurosurg Psychiatry 76 Suppl 5, v2-7, doi:10.1136/jnnp.2005.082867 (2005).

55 Kivimaki, M. et al. Association between socioeconomic status and the development of mental and physical health conditions in adulthood: a multi-cohort study. Lancet Public Health 5, e140-e149, doi:10.1016/S2468-2667(19)30248-8 (2020).

56 Wei, W. Q. et al. Combining billing codes, clinical notes, and medications from electronic health records provides superior phenotyping performance. J Am Med Inform Assoc 23, e20-27, doi:10.1093/jamia/ocv130 (2016).

57 Corraini, P., Olsen, M., Pedersen, L., Dekkers, O. M. \& Vandenbroucke, J. P. Effect modification, interaction and mediation: an overview of theoretical insights for clinical investigators. Clin Epidemiol 9, 331-338, doi:10.2147/CLEP.S129728 (2017).

58 Mao, H., Li, L., Yang, W. \& Shen, Y. On the propensity score weighting analysis with survival outcome: Estimands, estimation, and inference. Stat Med 37, 3745-3763, doi:10.1002/sim.7839 (2018).

59 Vakulenko-Lagun, B. et al. causalCmprsk: Nonparametric and Cox-Based Estimation of average treatment effects in Competing Risks, <https://cran.rproject.org/web/packages/causalCmprsk/index.html> (2021).

60 Cole, S. R. et al. Estimation of the standardized risk difference and ratio in a competing risks framework: application to injection drug use and progression to AIDS after initiation of antiretroviral therapy. American journal of epidemiology 181, 238-245, doi:10.1093/aje/kwu122 (2015).

61 Andersen, P. K., Geskus, R. B., de Witte, T. \& Putter, H. Competing risks in epidemiology: possibilities and pitfalls. Int J Epidemiol 41, 861-870, doi:10.1093/ije/dyr213 (2012).

62 Stensrud, M. J. \& Hernán, M. A. Why Test for Proportional Hazards? JAMA 323, 14011402, doi:10.1001/jama.2020.1267 (2020).

63 Hernan, M. A. The hazards of hazard ratios. Epidemiology 21, 13-15, doi:10.1097/EDE.0b013e3181c1ea43 (2010).

64 Ash, Peter E. A. et al. Unconventional Translation of <em>C9ORF72</em> GGGGCC Expansion Generates Insoluble Polypeptides Specific to c9FTD/ALS. Neuron 77, 639646, doi:10.1016/j.neuron.2013.02.004.

65 Rubin, D. B. \& Schenker, N. Multiple imputation in health-care databases: an overview and some applications. Statistics in medicine 10, 585-598 (1991). 
medRxiv preprint doi: https://doi.org/10.1101/2021.08.10.21261747; this version posted August 12, 2021. The copyright holder for this preprint (which was not certified by peer review) is the author/funder, who has granted medRxiv a license to display the preprint in perpetuity.

It is made available under a CC-BY-ND 4.0 International license .

$66<$ https://bcbio-nextgen.readthedocs.io/> (

67 Robinson, M. D., McCarthy, D. J. \& Smyth, G. K. edgeR: a Bioconductor package for differential expression analysis of digital gene expression data. Bioinformatics 26, 139140, doi:10.1093/bioinformatics/btp616 (2010).

68 Liberzon, A. et al. Molecular signatures database (MSigDB) 3.0. Bioinformatics 27, 1739-1740, doi:10.1093/bioinformatics/btr260 (2011).

69 Subramanian, A. et al. Gene set enrichment analysis: a knowledge-based approach for interpreting genome-wide expression profiles. Proc Natl Acad Sci U S A 102, 15545 15550, doi:10.1073/pnas.0506580102 (2005).

70 Macron, C., Lane, L., Núñez Galindo, A. \& Dayon, L. Deep Dive on the Proteome of Human Cerebrospinal Fluid: A Valuable Data Resource for Biomarker Discovery and Missing Protein Identification. Journal of Proteome Research 17, 4113-4126, doi:10.1021/acs.jproteome.8b00300 (2018).

71 Bihlmeyer, N. A. et al. Novel methods for integration and visualization of genomics and genetics data in Alzheimer's disease. Alzheimers Dement 15, 788-798, doi:10.1016/j.jalz.2019.01.011 (2019).

72 Yoshida, K. <(https://cran.r-project.org/web/packages/tableone/vignettes/smd.html) $>$ (2020).

73 Austin, P. C. An Introduction to Propensity Score Methods for Reducing the Effects of Confounding in Observational Studies. Multivariate Behav Res 46, 399-424, doi:10.1080/00273171.2011.568786 (2011).

\section{FIGURE LEGENDS}

Fig. 1 | Consort Diagrams for US RPDR and UK CPRD. (a) Flowchart of inclusion and exclusion criteria of study population in RPDR (b) Flowchart of inclusion and exclusion criteria of study population in CPRD.

Fig. 2 | Metformin reduces all-cause mortality relative to sulfonylureas among type II diabetic patients aged $>\mathbf{5 0}$ years at treatment initiation. (a, c) Kaplan-Meier survival curves for metformin and sulfonylurea initiators with 95\% Confidence Intervals (CI). N=\# of patients at baseline, $\mathrm{D}=\#$ of deaths during follow-up. Hazard Ratios (HR) were estimated using the Cox Proportional Hazards (PH) model, with only treatment as a covariate, and baseline covariate distributions between treatment arms balanced by Inverse Propensity score of Treatment Weighting (IPTW). (b, d) Forest plots presenting all-cause mortality HRs overall and stratified by age, sex, and BMI level at baseline, with sulfonylurea initiators as the reference group. Covariate balancing using IPTW was conducted in each stratum independently. 
medRxiv preprint doi: https://doi.org/10.1101/2021.08.10.21261747; this version posted August 12, 2021. The copyright holder for this preprint (which was not certified by peer review) is the author/funder, who has granted medRxiv a license to display the preprint in perpetuity.

It is made available under a CC-BY-ND 4.0 International license .

Fig. 3 | Metformin reduces incident dementia relative to sulfonylureas in type II diabetic patients aged $>50$ years at treatment initiation. HRs were estimated using the Cox PH model for the causespecific hazards of dementia, with only treatment as a covariate and baseline covariate distributions between treatment arms balanced by IPTW. $(\mathbf{a}, \mathbf{b})$ Forest plots present HRs overall and stratified by age, sex, and BMI level at baseline, with sulfonylureas as the reference group. $\mathrm{N}=\#$ of patients at baseline, Onsets=\# of patients with dementia onset during follow-up and prior to death. Covariate balancing using IPTW was conducted in each stratum independently.

Fig. 4 | Risk differences in dementia onset over time are negligible for metformin initiators, as compared to sulfonylureas. Cumulative incidence functions (CIF) or risk curves, along with their $95 \%$ CIs, were estimated using the Cox model for the cause-specific hazards, with only treatment as a covariate and baseline covariate distributions between treatment arms balanced by IPTW. (a, b) CIF curves for dementia onset (in blue hues) and competing death (in orange hues) for metformin vs. sulfonylurea initiators. Follow-up times are up to 12 and 16 years in the US RPDR (a) and the UK CPRD (b) cohorts, respectively. (c, d) Risk difference curves for dementia onset (in blue) and competing death (in orange), in the US RPDR (c) and the UK CPRD (d) cohorts, respectively. A negative risk difference value during certain time periods indicates that initiation of metformin is beneficial, as compared to sulfonylureas.

Fig. 5 | Differential gene expression in human neural cells triggered by metformin and glyburide: markedly reduced levels of the AD biomarker SPP1 (osteopontin). (a) Differentiated human ReN VM cells into neural cells were treated with metformin or glyburide at two different concentrations, for either 24 or $72 \mathrm{~h}$. (b) Genes with largest dose-dependent change in expression over 24 and $72 \mathrm{~h}$, for either metformin or glyburide - top 5 increased and top 5 decreased. (c) Genes expressing secreted proteins with greatest differential between metformin and glyburide. (d) SPP1 RNA levels in 4 different brain regions: $\mathrm{AD}$ vs. Controls (DLPFC $=$ dorsolateral prefrontal cortex; $\mathrm{PHG}=$ parahippocampal gyrus; $\mathrm{STS}=$ superior temporal sulcus; $\mathrm{TC}=$ temporal cortex). 


\begin{tabular}{|c|c|c|}
\hline $\begin{array}{l}\text { TARGET TRIAL } \\
\text { SPECIFICATION }\end{array}$ & EMULATION (US RPDR) & EMULATION (UK CPRD) \\
\hline \multicolumn{3}{|l|}{ Eligibility criteria } \\
\hline Age $\geq 50$ & \multicolumn{2}{|l|}{ Same } \\
\hline No hypoglycemics & \multicolumn{2}{|c|}{ No recorded prior exposure to any hypoglycemic agents } \\
\hline $\begin{array}{l}\text { No MCI*, dementia, or } \\
\text { prescription of dementia } \\
\text { drugs; normal cognitive } \\
\text { testing }\end{array}$ & $\begin{array}{l}\text { No recorded diagnosis of dementia or } \\
\text { MCI*, or use of dementia-specific } \\
\text { drugs (see Extended Data Tables 8-9) }\end{array}$ & $\begin{array}{l}\text { No recorded diagnosis of dementia } \\
\text { (MCI* diagnoses not available in } \\
\text { CPRD) or use of dementia-specific } \\
\text { drugs (see Extended Data Tables 10-11) }\end{array}$ \\
\hline $\begin{array}{l}\text { No chronic kidney disease } \\
\text { (metformin contraindication) }\end{array}$ & $\begin{array}{l}\text { No ICD*-9/10 code for chronic } \\
\text { kidney disease or eGFR } *<45 \\
\text { (Extended Data Table } 1)\end{array}$ & $\begin{array}{l}\text { No diagnosis of chronic kidney disease } \\
\text { at or prior to baseline (Extended Data } \\
\text { Table 2) }\end{array}$ \\
\hline $\begin{array}{l}\text { Trial with one-year run in } \\
\text { period conducted for a } \\
\text { specified duration with } \\
\text { history obtained at baseline } \\
\text { and ongoing monitoring of } \\
\text { outcomes }\end{array}$ & $\begin{array}{l}\text { - } \mathrm{PCP}^{*} \text { within Mass General } \\
\text { Brigham Health Care system EHR* } \\
\text { system } \\
\text { - At least one visit during the } 18 \\
\text { months preceding baseline } \\
\text { - At least one year of follow-up } \\
\text { - No dementia or death in first year }\end{array}$ & $\begin{array}{l}\text { - At least one-year registration in CPRD } \\
\text { practices before the first prescription } \\
\text { - At least one year of follow-up } \\
\text { - No dementia or death in first year }\end{array}$ \\
\hline \multicolumn{3}{|l|}{ Treatment strategies } \\
\hline $\begin{array}{l}\text { Treatment arm: metformin } \\
\text { monotherapy } \\
\text { Control arm: sulfonylurea } \\
\text { monotherapy }\end{array}$ & $\begin{array}{l}\text { Initiation of metformin or } \\
\text { sulfonylurea from } 1 / 2007-9 / 2017 \text { (see } \\
\text { Extended Data Fig. } 8 \text { for the number } \\
\text { of new prescriptions per year) }\end{array}$ & $\begin{array}{l}\text { Initiation of metformin or sulfonylurea } \\
\text { from } 1 / 2001-5 / 2017, \text { with } \geq 2 \\
\text { monotherapy prescriptions for first } 12 \\
\text { months (see Extended Data Fig. } 9 \text { for } \\
\text { the number of new prescriptions per } \\
\text { year) }\end{array}$ \\
\hline \multicolumn{3}{|l|}{ Treatment assignment } \\
\hline $\begin{array}{l}\text { Double-blind, randomized } \\
\text { treatment assignment }\end{array}$ & \multicolumn{2}{|c|}{$\begin{array}{l}\text { Emulated randomization by balancing baseline confounders using IPTW* for } \\
\text { treatment choice }\end{array}$} \\
\hline \multicolumn{3}{|l|}{ Outcomes } \\
\hline $\begin{array}{l}\text { Diagnosis of } \mathrm{MCI}^{*} \text { or } \\
\text { dementia }\end{array}$ & $\begin{array}{l}\text { Diagnosis of MCI/Dementia by: } \\
\text { ICD*-9/10 codes (Extended Data } \\
\text { Table 8) OR at least one dementia- } \\
\text { specific drug prescription (Extended } \\
\text { Data Table 9) }\end{array}$ & $\begin{array}{l}\text { Diagnosis of dementia by: Medcodes in } \\
\text { CPRD or ICD*-9/10 codes in linked } \\
\text { HES* or ONS* database (Extended } \\
\text { Data Table 10) OR at least one } \\
\text { dementia-specific drug prescription } \\
\text { (Extended Data Table } 11 \text { ) }\end{array}$ \\
\hline Time to death & \multicolumn{2}{|l|}{ Time to death recorded in EHR* } \\
\hline $\mathbf{F}$ & & \\
\hline
\end{tabular}


medRxiv preprint doi: https://doi.org/10.1101/2021.08.10.21261747; this version posted August 12, 2021. The copyright holder for this preprint (which was not certified by peer review) is the author/funder, who has granted medRxiv a license to display the preprint in perpetuity.

It is made available under a CC-BY-ND 4.0 International license.

\begin{tabular}{|l|l|}
\begin{tabular}{|l|l|} 
From baseline and ends at \\
dementia onset, death, lost to \\
follow-up, or end of study
\end{tabular} & $\begin{array}{l}\text { From the date of initial prescription of drug until the date of dementia incidence, } \\
\text { death, last encounter date, 9/2018 (US RPDR) or 5/2018 (UK CPRD), } \\
\text { whichever occurred first }\end{array}$ \\
\hline Causal contrast & Observational analog of intention-to-treat effect \\
\hline Intention-to-treat effect & \\
\hline Statistical analysis & $\begin{array}{l}\text { Intention-to-treat analysis using Cox Proportional Hazards (PH) regression } \\
\text { primary outcomes (dementia } \\
\text { and death) using Cox PH } \\
\text { Subgroup analyses by age, sex, and BMI* level at baseline }\end{array}$ \\
\hline
\end{tabular}

Table 1 | Specification and emulation of a target trial of antidiabetic drug metformin vs. sulfonylureas on the risk of death and dementia, using observational data from Electronic Health Records of the US RPDR and the UK CPRD. BMI=Body Mass Index; eGFR=estimated Glomerular Filtration Rate; HES=Hospital Episode Statistics; ICD=International Classification of Diseases; IPTW=Inverse Propensity score of Treatment Weighting; MCI=Mild Cognitive Impairment; ONS=Office for National Statistics; PCP=Primary Care Physician. 
medRxiv preprint doi: https://doi.org/10.1101/2021.08.10.21261747; this version posted August 12, 2021. The copyright holder for this preprint (which was not certified by peer review) is the author/funder, who has granted medRxiv a license to display the preprint in perpetuity.

It is made available under a CC-BY-ND 4.0 International license .

\begin{tabular}{|c|c|c|c|c|}
\hline & \multicolumn{2}{|c|}{ US RPDR cohort $(\mathrm{N}=13,191)$} & \multicolumn{2}{|c|}{ UK CPRD cohort $(\mathrm{N}=108,025)$} \\
\hline Patient characteristics & $\begin{array}{c}\text { Metformin } \\
\text { initiators } \\
(\mathrm{n}=11,229)\end{array}$ & $\begin{array}{c}\text { Sulfonylurea } \\
\text { initiators } \\
(\mathrm{n}=1,962)\end{array}$ & $\begin{array}{c}\text { Metformin } \\
\text { initiators } \\
(\mathrm{n}=94,208)\end{array}$ & $\begin{array}{l}\text { Sulfonylurea } \\
\text { initiators } \\
(\mathrm{n}=13,817)\end{array}$ \\
\hline Age at baseline (mean, years) & 68.6 & 72.2 & 64.9 & 70.2 \\
\hline Sex (\% male) & 49.2 & 52.9 & 57.4 & 58.3 \\
\hline \multicolumn{5}{|l|}{ Race (percent) } \\
\hline White & 78.2 & 83.4 & 86.5 & 87.0 \\
\hline Black or African American & 7.6 & 5.4 & 3.6 & 3.0 \\
\hline Asian & 4.4 & 3.7 & \multicolumn{2}{|c|}{ Data combined with Other } \\
\hline Other & 9.8 & 7.5 & 9.9 & 10.0 \\
\hline Ethnicity (\% Hispanic) & 4.4 & 3.3 & \multicolumn{2}{|c|}{ Data not available } \\
\hline Year of first prescription (median) & 2012 & 2012 & 2008 & 2003 \\
\hline SES/IMD* (\% low income/most deprived) & 3.1 & 1.8 & 17.3 & 17.5 \\
\hline Cancer (\%) & 30.2 & 28.7 & 9.9 & 12.4 \\
\hline $\mathrm{CVD}^{* *}(\%)$ & 42.8 & 44.4 & 53.8 & 50.8 \\
\hline Hypertension (\%) & 74.2 & 67.0 & 94.9 & 90.7 \\
\hline COPD (\%) & \multirow{2}{*}{\multicolumn{2}{|c|}{ Data not available }} & 4.7 & 4.6 \\
\hline Smoker* (\%) & & & 17.0 & 18.7 \\
\hline Stroke** (\%) & 11.9 & 12.1 & \multicolumn{2}{|c|}{ Data combined with CVD } \\
\hline \multicolumn{5}{|l|}{ Baseline HbA1C level* (percent) } \\
\hline$<7(\%)$ & 51.8 & 46.2 & 16.4 & 11.8 \\
\hline $7-10(\%)$ & 42.0 & 47.9 & 69.1 & 65.3 \\
\hline$>10(\%)$ & 6.2 & 5.9 & 14.5 & 22.9 \\
\hline \multicolumn{5}{|l|}{ Baseline BMI* $\left(\mathrm{kg} / \mathrm{m}^{2}\right)$} \\
\hline$<25(\%)$ & 11.1 & 17.5 & 8.1 & 34.8 \\
\hline $25-30(\%)$ & 29.5 & 36.0 & 32.9 & 43.5 \\
\hline$\geq \mathbf{3 0}(\%)$ & 59.4 & 46.5 & 59.0 & 21.7 \\
\hline \multicolumn{5}{|l|}{ All-cause mortality analysis outcomes } \\
\hline Median follow-up time (years) & 5.3 & 5.3 & 6.0 & 7.0 \\
\hline Total person-years & 63,060 & 11,047 & 592,948 & 103,777 \\
\hline Deaths (n, \%) & $527(4.7)$ & $222(11.3)$ & $12,941(13.7)$ & $5,173(37.4)$ \\
\hline \multicolumn{5}{|l|}{ Competing risk analysis outcomes } \\
\hline Median follow-up time (years) & 5.0 & 5.0 & 6.0 & 7.0 \\
\hline Total person-years & 60,683 & 10,508 & 592,072 & 103,209 \\
\hline Deaths prior to dementia (n, \%) & $415(3.7)$ & $154(7.8)$ & $11,560(12.3)$ & $4,570(33.1)$ \\
\hline Incident dementia cases (n, \%) & $869(7.7)$ & $241(12.3)$ & $5.561(5.9)$ & $1,699(12.3)$ \\
\hline
\end{tabular}

Table 2 | Baseline characteristics of eligible individuals when emulating a target trial of metformin vs. sulfonylurea initiators on the risk of death and dementia in the US RPDR (2007-2017) and the

UK CPRD (2001-2017). SES (US RPDR) and IMD (UK CPRD) are distinct, country-specific socioeconomic indicators, intended for comparison within - rather than across - the two cohorts. BMI=Body Mass Index; COPD=Chronic Obstructive Pulmonary Disease; CVD=Cardio-Vascular Disease; HbA1C=glycosylated hemoglobin. IMD=Index of Multiple Deprivation (official measure of relative deprivation by small geographic region in the UK). IMD, smoking status, HbA1C, and BMI had $7 \%, 2 \%, 21 \%$, and $3 \%$ of missing values in the UK CPRD, respectively. The corresponding statistics presented in the table are valid percentages out of patients without missing information. **Stroke and CVD indicators were collapsed. 
Fig. 1 | Consort Diagrams for US RPDR and UK CPRD.

Flowchart of inclusion and exclusion criteria of study population in US RPDR

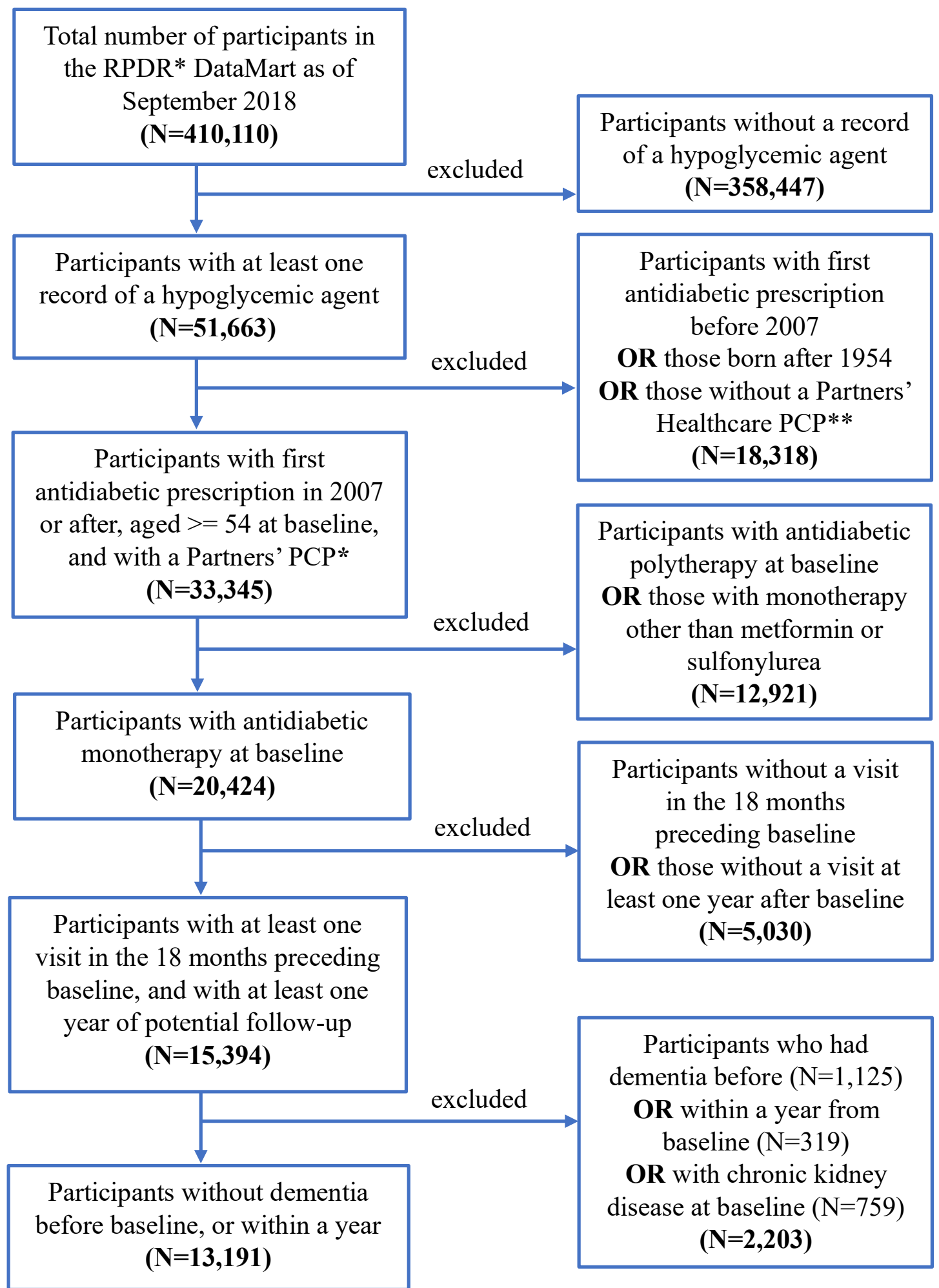




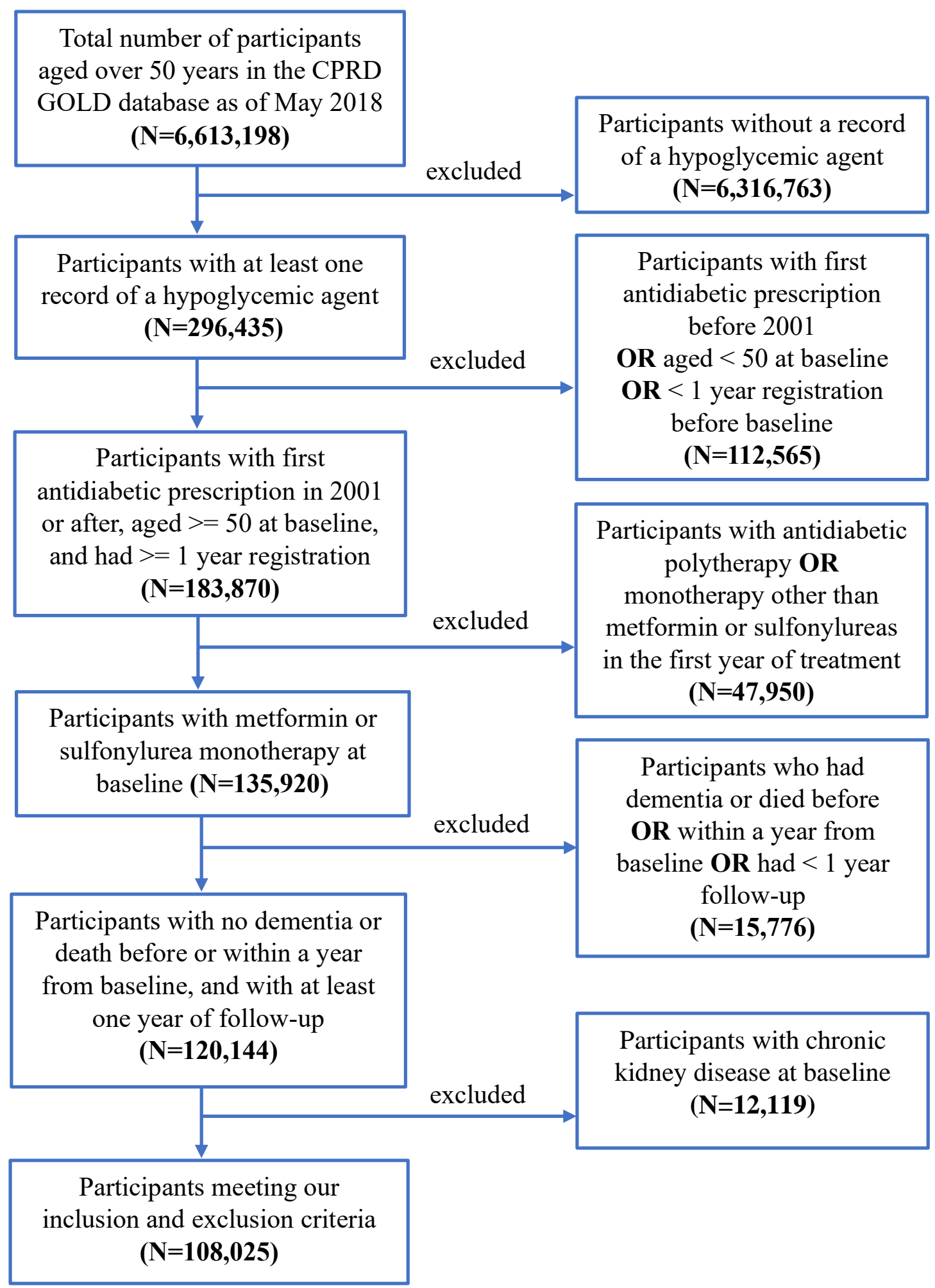


medRxiv preprint doi: https://doi.org/10.1101/2021.08.10.21261747; this version posted August 12, 2021. The copyright holder for this preprint (which was not certified by peer review) is the author/funder, who has granted medRxiv a license to display the preprint in perpetuity.

Fig. 2

a

US RPDR:

All-Cause Mortality Survival Curves Metformin vs. Sulfonylureas (reference)

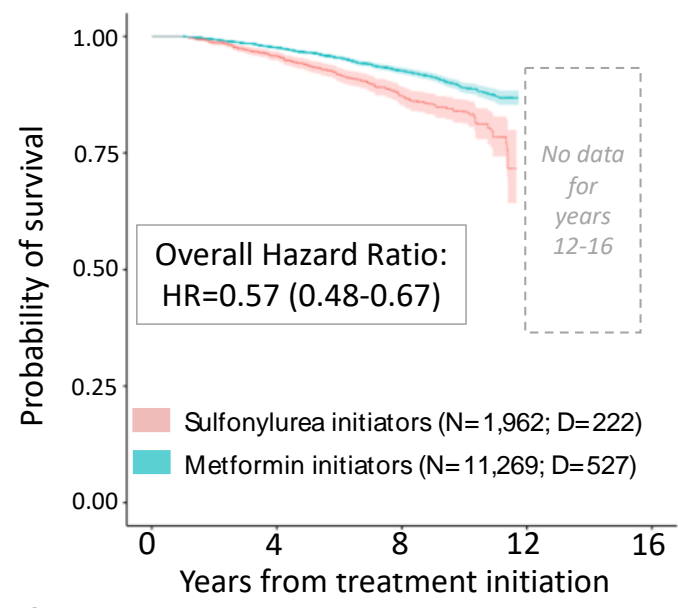

C

UK CPRD:

All-Cause Mortality Survival Curves Metformin vs. Sulfonylureas (reference)

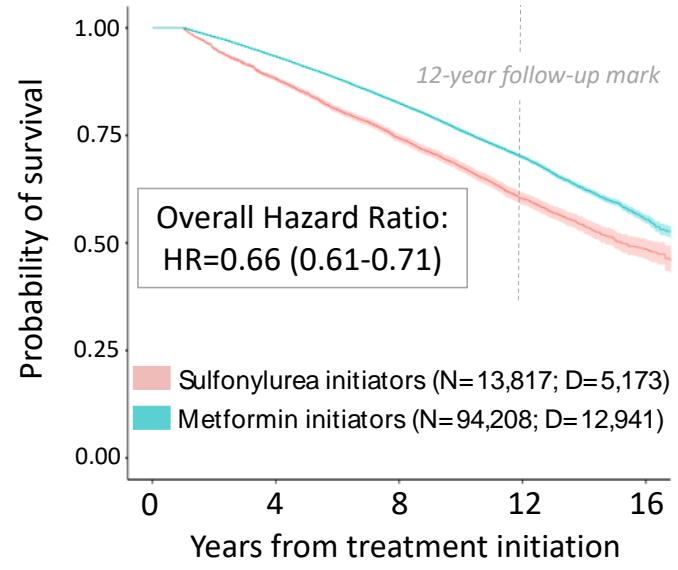

b

US RPDR: HR for All-Cause Mortality Overall and stratified by age, sex, and BMI

\begin{tabular}{|c|c|c|c|c|c|}
\hline \multicolumn{2}{|c|}{ Subgroup } & $\mathbf{N}$ & Deaths & HR $(95 \% \mathrm{Cl})$ & $P$-value \\
\hline Overall & $-\rightarrow$ & 13191 & 749 & $0.57(0.48-0.67)$ & $<0.001$ \\
\hline \multicolumn{6}{|c|}{ Age (year) } \\
\hline$\leq 70$ & $\longrightarrow$ & 8209 & 324 & $0.56(0.43-0.74)$ & $<0.001$ \\
\hline$>70$ & $\rightarrow$ & 4982 & 425 & $0.58(0.47-0.71)$ & $<0.001$ \\
\hline \multicolumn{6}{|l|}{ Sex } \\
\hline male & $\bullet-$ & 6560 & 420 & $0.57(0.46-0.70)$ & $<0.001$ \\
\hline female & $\longrightarrow$ & 6631 & 329 & $0.59(0.45-0.76)$ & $<0.001$ \\
\hline \multicolumn{6}{|c|}{ BMI (kg/m²) } \\
\hline$<25$ & & 1068 & 75 & $0.82(0.47-1.42)$ & 0.472 \\
\hline $25-30$ & $\bullet$ & 2733 & 152 & $0.63(0.44-0.92)$ & 0.017 \\
\hline$\geq 30$ & - & 5205 & 214 & $0.78(0.53-1.15)$ & 0.206 \\
\hline
\end{tabular}

d

UK CPRD: HR for All-Cause Mortality Overall and stratified by age, sex, and BMI

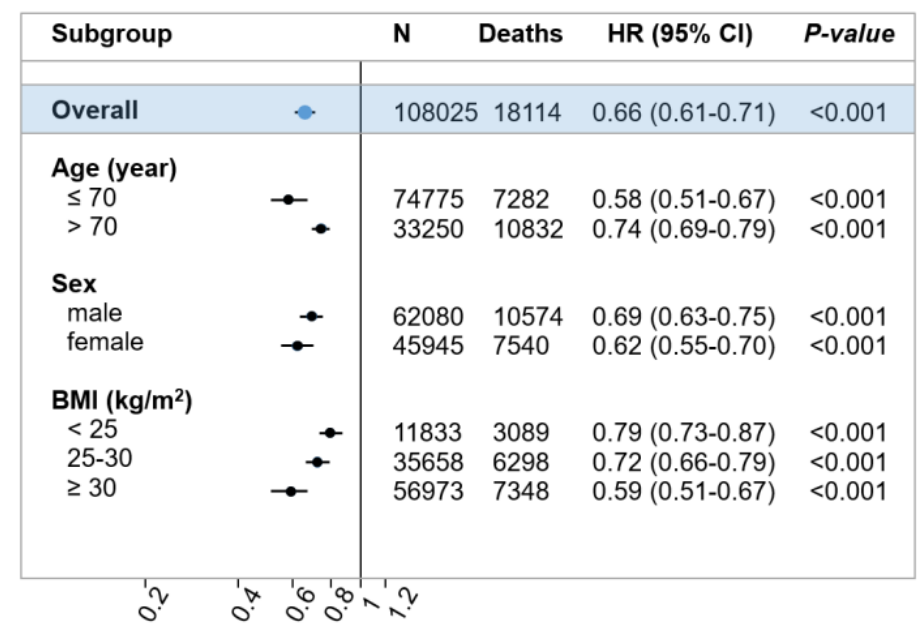


medRxiv preprint doi: https://doi.org/10.1101/2021.08.10.21261747; this version posted August 12, 2021. The copyright holder for this preprint (which was not certified by peer review) is the author/funder, who has granted medRxiv a license to display the preprint in perpetuity.

\section{It is made available under a CC-BY-ND 4.0 International license .}

Fig. 3

HR for Dementia Onset

Metformin vs. Sulfonylureas (reference)

Overall and stratified by age, sex, and BMI

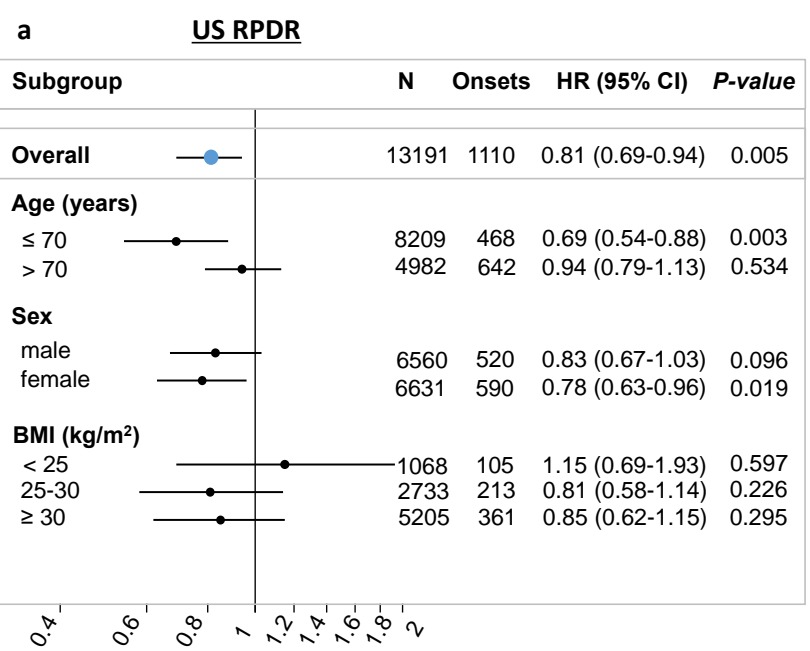

\section{b $\quad$ UK CPRD}

\begin{tabular}{|c|c|c|c|c|c|}
\hline \multicolumn{2}{|c|}{ Subgroup } & $\mathbf{N}$ & Onsets & HR $(95 \% \mathrm{Cl})$ & P-value \\
\hline Overall & $-\bullet-$ & 108025 & 7260 & $0.86(0.77-0.96)$ & 0.007 \\
\hline \multicolumn{6}{|c|}{ Age (years) } \\
\hline$\leq 70$ & & 74775 & 2238 & $0.82(0.67-0.99)$ & 0.041 \\
\hline$>70$ & & 33250 & 5022 & $0.88(0.77-0.99)$ & 0.035 \\
\hline \multicolumn{6}{|l|}{ Sex } \\
\hline male & & 62080 & 3476 & $0.88(0.76-1.01)$ & 0.064 \\
\hline female & & 45945 & 3784 & $0.86(0.73-1.01)$ & 0.062 \\
\hline \multicolumn{6}{|c|}{ BMI $\left(\mathrm{kg} / \mathrm{m}^{2}\right)$} \\
\hline$<25$ & & 11833 & 1365 & $0.94(0.83-1.07)$ & 0.341 \\
\hline $25-30$ & & 35658 & 2798 & $0.92(0.82-1.05)$ & 0.208 \\
\hline$\geq 30$ & & 56973 & 2690 & $0.89(0.72-1.11)$ & 0.299 \\
\hline & & & & & \\
\hline $0^{x}$ & 0 & ? & & & \\
\hline
\end{tabular}


medRxiv preprint doi: https://doi.org/10.1101/2021.08.10.21261747; this version posted August 12, 2021. The copyright holder for this preprint (which was not certified by peer review) is the author/funder, who has granted medRxiv a license to display the preprint in perpetuity.

Fig. 4

\section{Cumulative Incidence Function (CIF) curves for dementia onset and for death Metformin vs. Sulfonylureas}
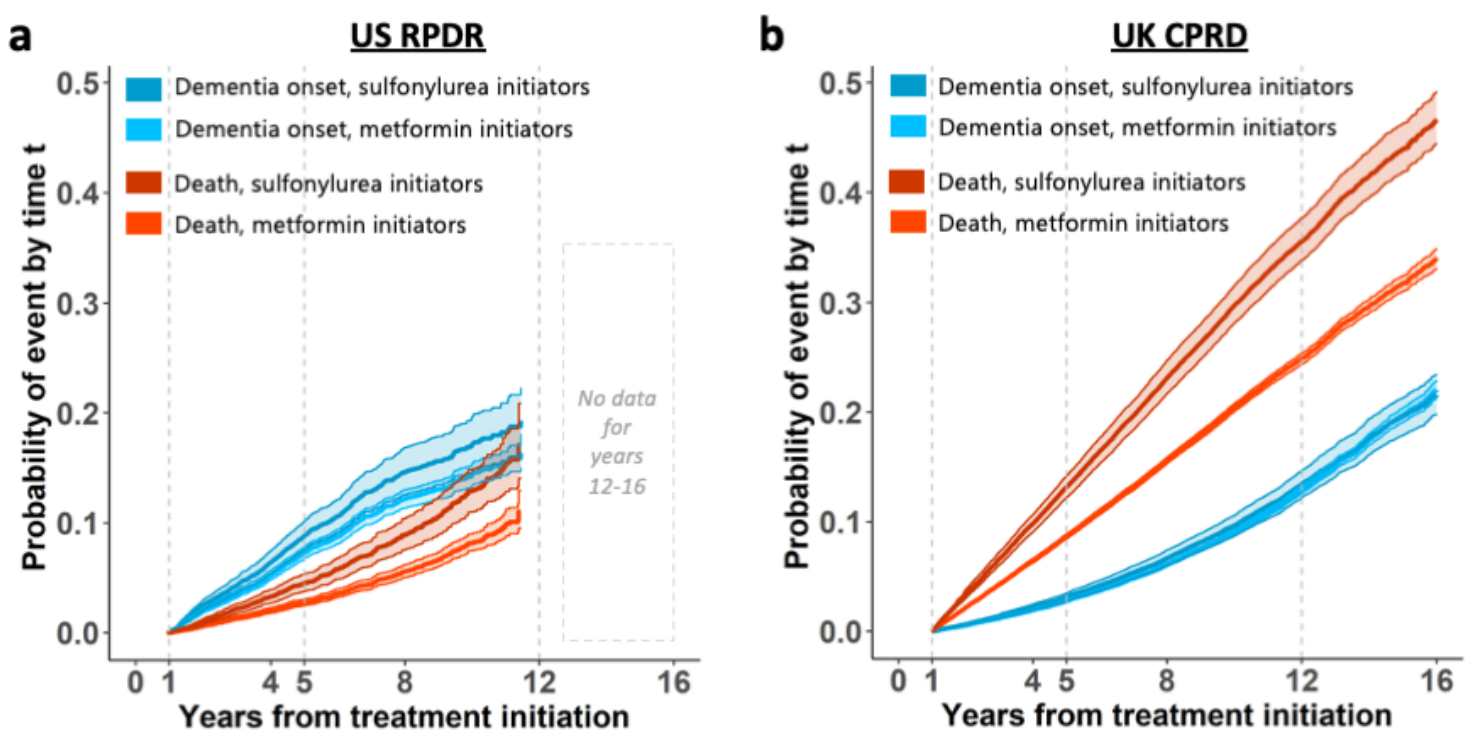

\section{Risk differences in dementia onset and death Metformin vs. Sulfonylureas (reference)}
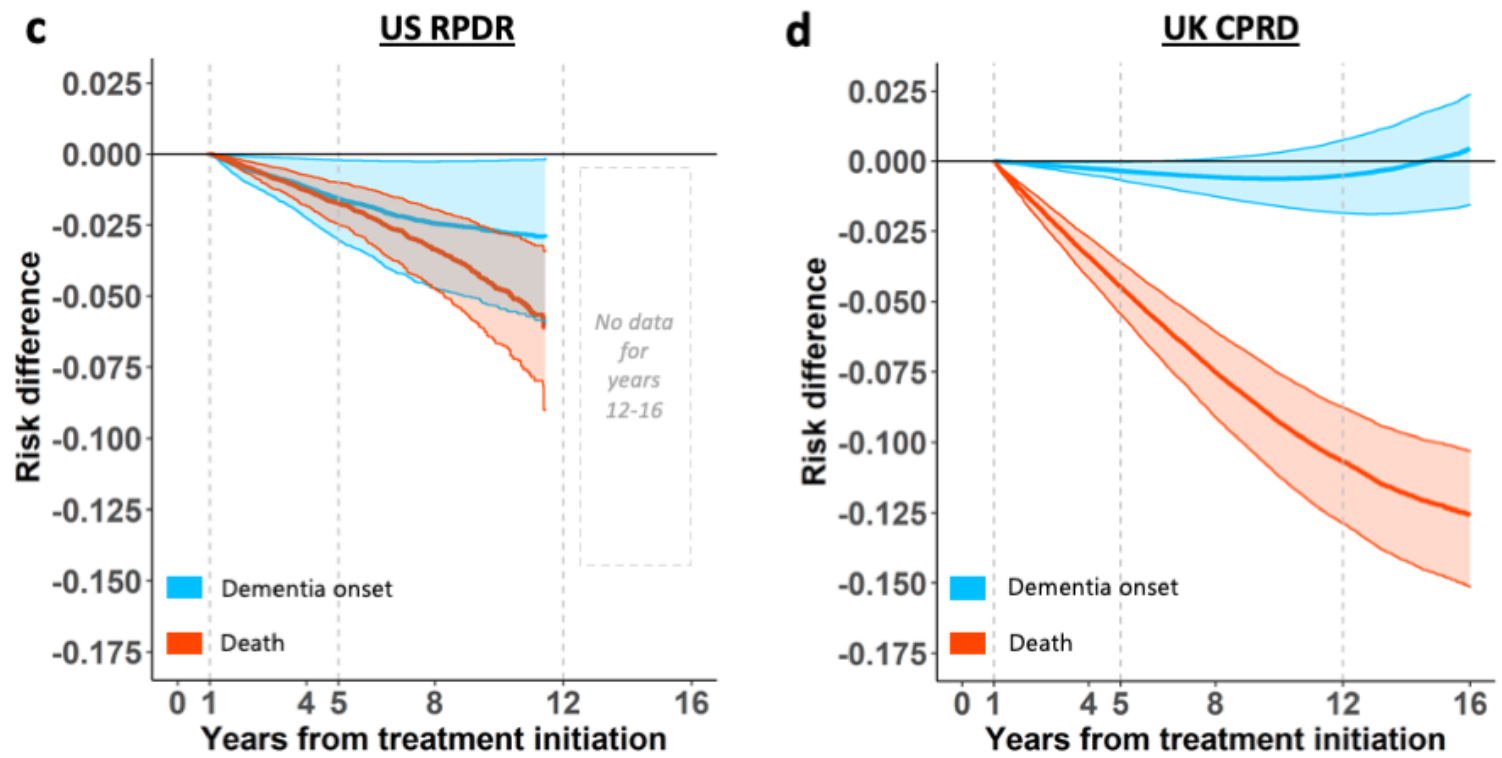
medRxiv preprint doi: https://doi.org/10.1101/2021.08.10.21261747; this version posted August 12, 2021. The copyright holder for this preprint (which was not certified by peer review) is the author/funder, who has granted medRxiv a license to display the preprint in perpetuity.

It is made available under a CC-BY-ND 4.0 International license.

Fig. 5

b
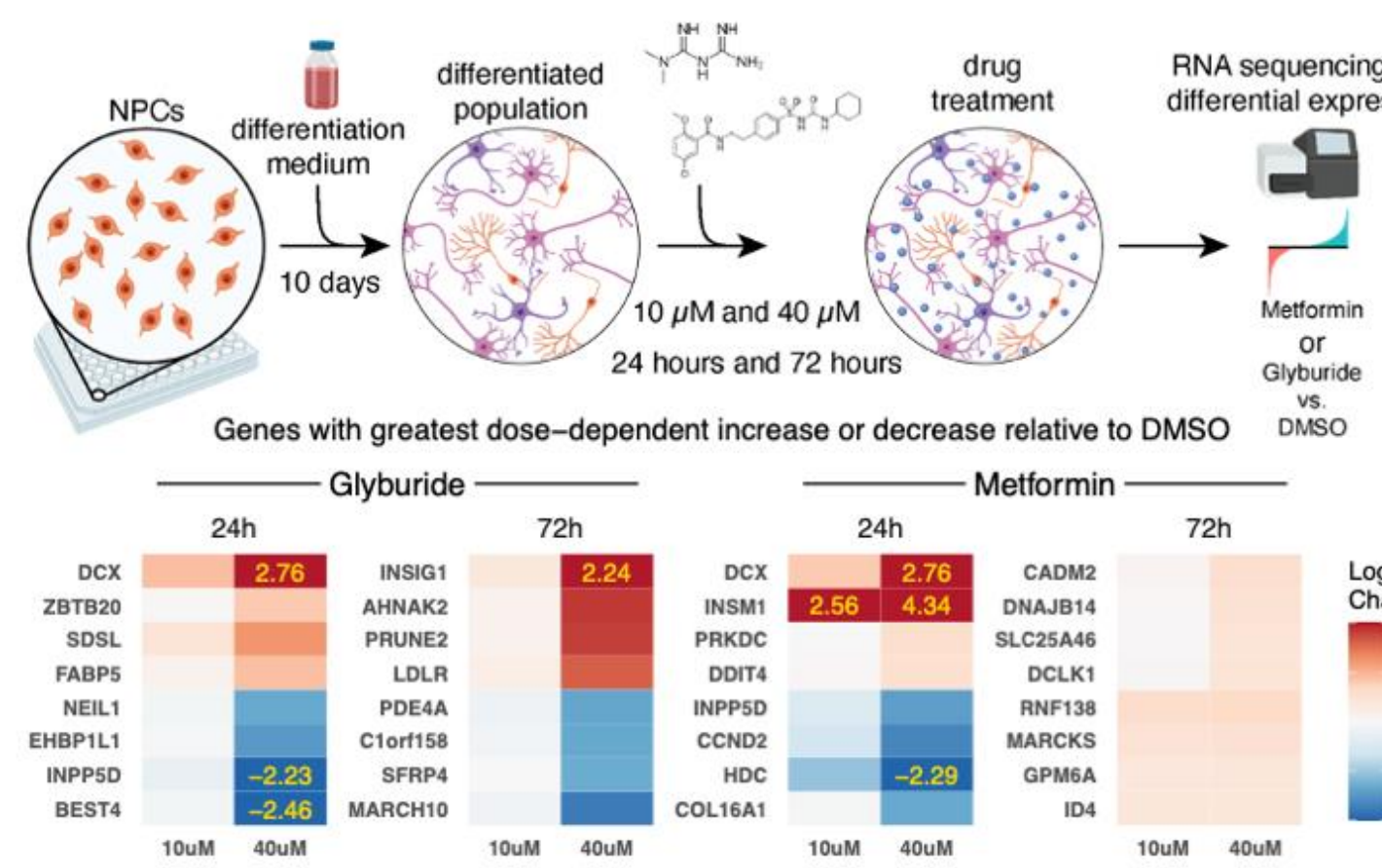

C RNA levels of secreted proteins, metformin vs. glyburide
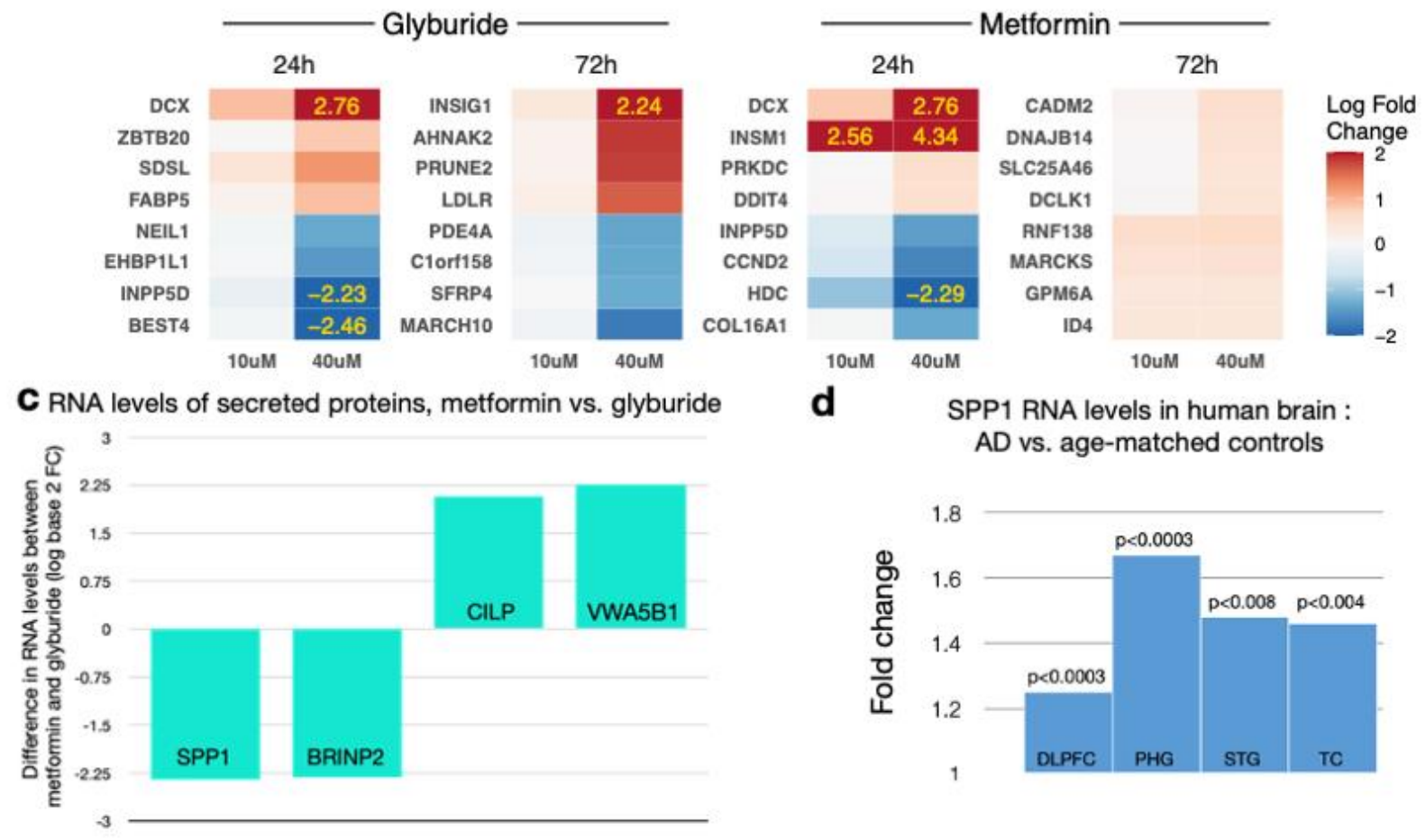

d SPP1 RNA levels in human brain :

$A D$ vs. age-matched controls

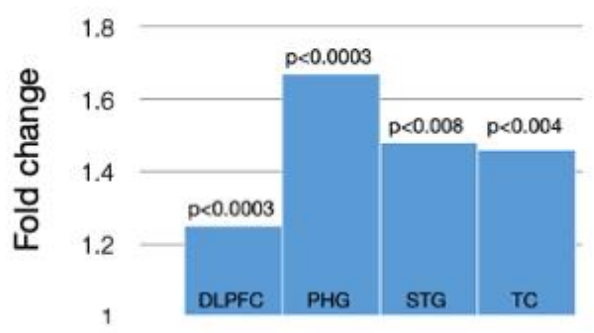




\section{METHODS}

\section{Data sources}

The data used in the study are from two large-scale EHR databases: the Research Patient Data Registry in the United States at Mass General Brigham Healthcare (US RPDR) and the Clinical Practice Research Datalink in the United Kingdom (UK CPRD).

US RPDR. The study cohort was selected from the RPDR registry ${ }^{13}$. RPDR is a longitudinal centralized clinical data registry with $\sim 6.5$ million patients mainly from the Boston area as of June 2020. The data are collected from EHR systems within Mass General Brigham (MGB) Healthcare (formerly Partners Healthcare), comprising two major academic hospitals, as well as several community hospitals and community health centers in the Boston area. Death records are updated periodically from the US Social Security Death Index (2007-2017). Use of RPDR data for this study was approved by the institutional review board (IRB) of MGB.

UK CPRD. The study cohort was selected from the CPRD database ${ }^{14}$. CPRD is a longitudinal national primary care database, with $\sim 17$ million patients from 13 regions across the UK. The data are collected from EHR systems in general practice physician (GP) practices. GP practices can enroll the CPRD data system on an ongoing basis and can leave it at any time. Over 700 GP practices (8\% of total GP practices) have contributed data to CPRD and the mean follow-up time for patients included in CPRD is around eight years. Death records are updated periodically from the UK Office of National Statistics (ONS). Additionally, data linkages were established with secondary care data from Hospital Episode Statistics (HES) as well as with small-area measures of social deprivation (2001-2017). Use of CPRD data for this study was approved by the Independent Scientific Advisory Committee (ISAC) for Medicines and Healthcare products Regulatory Agency (MHRA) database research (protocol number: 19_065R).

Both the US RPDR and the UK CPRD data includes patient demographics; encounter details such as dates, providers, diagnoses, and procedures; medical notes, drug prescriptions, and laboratory test results. We reported our findings according to the RECORD reporting guidelines ${ }^{45}$.

\section{Study population}

The eligibility criteria satisfied by the US RPDR and the UK CPRD populations are: 


\begin{tabular}{|c|c|c|}
\hline Criterion & US RPDR & UK CPRD \\
\hline $\begin{array}{l}\text { a) Time period spanned by the } \\
\text { observational study }\end{array}$ & $\begin{array}{l}\text { For the emulated trial in the } \\
\text { RPDR database, we included } \\
\text { patients with initial prescriptions } \\
\text { of metformin or sulfonylureas } \\
\text { between January } 2007 \text { and } \\
\text { September } 2017 .\end{array}$ & $\begin{array}{l}\text { For the emulated trial in the } \\
\text { CPRD database, we included } \\
\text { patients with initial prescriptions } \\
\text { of metformin or sulfonylureas } \\
\text { between January } 2001 \text { and May } \\
2017 \text {. }\end{array}$ \\
\hline b) Minimum age at baseline & \multicolumn{2}{|c|}{$\begin{array}{l}\text { We included patients over } 50 \text { years old at the first prescription date } \\
\text { (time } 0 \text {, or baseline). }\end{array}$} \\
\hline $\begin{array}{l}\text { c) Prior history of primary care } \\
\text { within the system, in order to: } \\
\text { - allow sufficient time for } \\
\text { baseline patient information to } \\
\text { be recorded and reduce the } \\
\text { likelihood of data missingness } \\
\text { - ensure the patient is a new } \\
\text { antidiabetic drug user at baseline } \\
\text { and maximize the duration of } \\
\text { their follow-up }\end{array}$ & $\begin{array}{l}\text { Have a primary care physician } \\
\text { (PCP) within MGB before the } \\
\text { first prescription of antidiabetic } \\
\text { drugs. To identify patients with } \\
\text { a MGB PCP, the presence of at } \\
\text { least one of the following was } \\
\text { required: i) a CPT code for } \\
\text { preventative medicine services, } \\
\text { ii) an annual exams/wellness } \\
\text { visit in the EHR, or iii) an } \\
\text { encounter from selected } \\
\text { departments (family medicine, } \\
\text { general practice, general internal } \\
\text { medicine, or preventative care). }\end{array}$ & $\begin{array}{l}\text { Have at least one-year } \\
\text { registration in a CPRD practice } \\
\text { before the first prescription of } \\
\text { antidiabetic drugs. }\end{array}$ \\
\hline $\begin{array}{l}\text { d) Metformin- and sulfonylurea- } \\
\text { monotherapy assignment }\end{array}$ & $\begin{array}{l}\text { The assignment of patients to } \\
\text { the metformin- and the } \\
\text { sulfonylurea-monotherapy } \\
\text { group was based on the first } \\
\text { record of prescription of either } \\
\text { drug. Only one prescription was } \\
\text { required. Prescriptions of } \\
\text { antidiabetic medications was } \\
\text { obtained from RPDR (see } \\
\text { Methods, section III). The }\end{array}$ & $\begin{array}{l}\text { The assignment of patients to } \\
\text { the metformin- and the } \\
\text { sulfonylurea-monotherapy } \\
\text { group was based on the first } \\
\text { record of prescription of either } \\
\text { drug. At least two consistent } \\
\text { prescriptions during the initial } \\
\text { 12-month treatment period were } \\
\text { required. Prescriptions of } \\
\text { antidiabetic medications were }\end{array}$ \\
\hline
\end{tabular}




\begin{tabular}{|c|c|c|}
\hline & $\begin{array}{l}\text { metformin monotherapy group } \\
\text { included patients who were } \\
\text { prescribed at baseline only } \\
\text { metformin; the sulfonylurea } \\
\text { monotherapy group included } \\
\text { patients who at baseline were } \\
\text { prescribed only sulfonylureas. }\end{array}$ & $\begin{array}{l}\text { obtained from CPRD using } \\
\text { British National Formulary } \\
\text { codes (see Methods, section III). } \\
\text { The metformin monotherapy } \\
\text { group included patients who } \\
\text { were exposed only to metformin } \\
\text { during their initial 12-month } \\
\text { treatment period; the } \\
\text { sulfonylurea monotherapy group } \\
\text { included patients who were } \\
\text { exposed only to sulfonylureas } \\
\text { during their initial 12-month } \\
\text { treatment period. }\end{array}$ \\
\hline $\begin{array}{l}\text { e) Absence of dementia } \\
\text { diagnosis at baseline }\end{array}$ & \multicolumn{2}{|c|}{$\begin{array}{l}\text { Have no dementia diagnosis or dementia-specific drug prescription } \\
\text { before the baseline date (see Section IV). }\end{array}$} \\
\hline f) Over one year of follow-up & \multicolumn{2}{|c|}{$\begin{array}{l}\text { Have one-year of follow-up after treatment initiation. } \\
\text { Have no dementia or death record during the first year of follow-up. }\end{array}$} \\
\hline $\begin{array}{l}\text { g) Absence of chronic kidney } \\
\text { disease (CKD) diagnosis at } \\
\text { baseline }\end{array}$ & \multicolumn{2}{|c|}{$\begin{array}{l}\text { Have no CKD diagnosis at the time of metformin- or sulfonylurea- } \\
\text { monotherapy treatment initiation, since CKD is a contraindication } \\
\text { for metformin. }{ }^{46}\end{array}$} \\
\hline Resulting sample size & $\begin{array}{l}\text { A total of } 13,191 \text { patients in } \\
\text { RPDR met these eligibility } \\
\text { criteria and were included in the } \\
\text { analyses (see Fig. 1a for the US } \\
\text { RPDR consort diagram). }\end{array}$ & $\begin{array}{l}\text { A total of } 108,025 \text { eligible } \\
\text { patients in CPRD met these } \\
\text { eligibility criteria and were } \\
\text { included in the analyses (see } \\
\text { Fig. 1b for the UK CPRD } \\
\text { consort diagram). }\end{array}$ \\
\hline
\end{tabular}

\section{Exposure assessment}

In both cohorts, any patients in combination therapy at baseline, including with insulin, were excluded.

We first identified individuals who met the eligibility criteria and assigned them to the treatment indicated in their medical record at baseline. The sulfonylurea monotherapy group included patients who were exposed only to sulfonylureas, including first generation (tolbutamide, chlorpropamide, tolazamide, or acetohexamide) and second generation (gliclazide, glibenclamide, glipizide, glimepiride, gliquidone, 
medRxiv preprint doi: https://doi.org/10.1101/2021.08.10.21261747; this version posted August 12, 2021. The copyright holder for this preprint (which was not certified by peer review) is the author/funder, who has granted medRxiv a license to display the preprint in perpetuity.

It is made available under a CC-BY-ND 4.0 International license .

glibornuride, or glymidine sodium). Similarly, the metformin monotherapy group included those who were exposed only to metformin (Extended Data Figs. 8-9).

\section{Dementia outcome ascertainment}

In both the US RPDR and the UK CPRD cohorts, the date of dementia onset was defined as the first dementia diagnosis date or the first prescription date of dementia-specific drugs, whichever occurred earlier.

US RPDR. In RPDR, dementia incidence was defined by the presence of either one or several dementia diagnosis codes (expertly curated list of International Classification of Diseases (ICD) codes including: a) ICD10 codes: 290.X, 294.X, and 331.X; b) ICD9 codes: 780.93, G30.X, and G31.X (Extended Data Table 8), and/or by the initiation of drugs primarily used for dementia (Donepezil, Galantamine, Rivastigmine, and their respective brand names Aricept, Razadyne, Exelon (Extended Data Table 9)).

UK CPRD. In CPRD, dementia incidence was defined by the presence of either one or several dementia diagnosis codes (expertly curated list including: a) a selected set of CPRD Medcodes: see Extended Data Table 10 for the detailed code list; b) ICD 9/10 codes in linked HES or ONS databases: see Extended Data Table 11 for the detailed code list), and/or by the initiation of drugs primarily used for dementia (Donepezil, Galantamine, Rivastigmine, or Memantine (Extended Data Table 11)).

We performed an intention-to-treat analysis. We were interested in assessing the comparative effectiveness of metformin- vs. sulfonylurea-monotherapy on time-to-dementia-onset in the presence of competing death, in the population of people who survived a year post baseline without dementia.

\section{Covariates}

Confounder selection. We considered all available covariates that potentially influence both the treatment assignment and one or both outcomes, or strongly related to at least one of the outcomes: dementia or death ${ }^{47,48}$. To harmonize the confounders included in the dementia onset and death model, we considered covariates that were influencing either outcome. Solely data-driven approaches to covariate selection can negatively affect the precision of the estimates and even amplify the residual bias ${ }^{49,50}$, and are a particular concern in EHR research, where informative missingness is the rule ${ }^{37,38}$. When adjusting for sources of confounding, both VanderWeele ${ }^{47}$ and Brookhart et al. ${ }^{50}$ recommend including covariates that are weakly related to the treatment assignment but are strongly related to the outcome of interest. 
Specifically, we included the following covariates. Age is the largest risk factor for dementia ${ }^{51}$ and death, and hence was included as a covariate. Since the UK CPRD observational study was spanning a longer time period (2000-2017) than the US RPDR (2007-2017), the calendar year of the first prescription was added to control for temporal changes in prescribing practices, mortality trends, and age-specific incidences of dementia ${ }^{11}$. Given that the US RPDR cohort captures patients who initiated after the new antidiabetic treatment recommendations formulated in 2006, there were no specific concerns about a potential shift in prescription patterns. It is unknown whether sex affects antidiabetic treatment assignment, but it strongly relates to the death outcome and may affect the dementia outcome beyond its effect on survival ${ }^{39,52,53}$. In addition, there might be sex-based differences in disease detection and reporting in the medical records, resulting in women having a higher incidence of dementia than men, as documented in the EHR. Therefore, we included both age at baseline (as a continuous covariate) and sex in the model. Hypertension, cardiovascular diseases (CVD), and stroke are also associated with dementia, and hence were also considered ${ }^{54}$. We included body mass index (BMI) at treatment initiation, and baseline levels of $\mathrm{HbA1C}$, which measures the average blood sugar levels over a period of about three months and the severity of diabetes. Socioeconomic status (SES) is associated with both dementia and death outcomes ${ }^{55}$. Finally, cancer is associated with death. For a patient to be categorized as having a history of cancer at baseline, we required at least two instances of cancer ICD codes in the EHR. The choice was based on previous literature, which suggested that accuracy is highest with two instances of cancer ICD $\operatorname{codes}^{56}$.

In both cohorts, information on the following covariates before the baseline date was extracted: age at the first prescription, sex, SES (index of multiple deprivation (IMD) in the UK CPRD and median annual household income by zip code in the US RPDR), BMI $\left(<25,25-30, \geq 30 \mathrm{~kg} / \mathrm{m}^{2}\right.$, or missing), HbA1C ( $<7 \%, 7-10 \%,>10 \%$, or missing), and comorbidities (hypertension, CVD, stroke, and cancer). Additional covariates which were not available in the US RPDR dataset were extracted in the UK CPRD cohort, including smoking status (non-smoker, current smoker, ex-smoker, or missing), and presence of chronic obstructive pulmonary disease (COPD) before baseline. Whereas the US RPDR cohort mainly includes patients living in the Boston area, the UK CPRD cohort is representative of patients nationally. To adjust for the geographical heterogeneity, the region of residence was additionally incorporated in the UK CPRD (as a categorical covariate with 12 levels and the reference).

Emulation of baseline randomization. The covariates defined above were used to emulate baseline randomization. We adjusted for confounding by rebalancing the metformin- and sulfonylurea-treatment groups, using Inverse Propensity score Treatment Weighting (IPTW). For both our analyses, all-cause mortality and competing risks, we used the same IPTW approach and the same set of confounders. The 
medRxiv preprint doi: https://doi.org/10.1101/2021.08.10.21261747; this version posted August 12, 2021. The copyright holder for this preprint (which was not certified by peer review) is the author/funder, who has granted medRxiv a license to display the preprint in perpetuity.

It is made available under a CC-BY-ND 4.0 International license.

contribution of each participant was reweighted to achieve balanced treatment arms with respect to a set of measured confounders.

In the US RPDR, we chose not to include two covariates, SES and history of stroke. In the UK CPRD, the IMD covariate was included, and the history of stroke was relatively rare (7\%) and was combined with CVD in a single covariate for simplicity. In the US RPDR study population, there was essentially no variability in the SES variable, as $96 \%$ of the cohort had a family income greater than the US poverty threshold, and there was almost no difference between the treatment groups (96\% and 97\% among metformin and sulfonylurea initiators). For stroke, there was somewhat more variability $-12 \%$ of the US RPDR cohort had an indication of prior stroke at treatment initiation, but there was almost no difference between the treatment groups ( $11.9 \%$ of metformin and $12.1 \%$ of sulfonylurea initiators).

Let $A$ be the treatment assignment random variable with $A=1$ for metformin and $A=0$ for sulfonylureas. Let $C$ be a set of confounders. We estimated propensity scores defined as follow: $p s_{i}=$ $P\left(A=a_{i} \mid C=c_{i}\right)$ for individual $i$ with treatment $A=a_{i}$ and covariates $C=c_{i}$, by fitting a logistic regression model. We denote the estimates of $p s_{i}$ by $\widehat{p s_{l}}$. Subject-specific weights were obtained by $\widehat{w_{l}^{*}}=$ $1 / \widehat{p s_{l}}$, i.e., by inverse-probability of being assigned to the actual treatment $A=a_{i}$. To reduce the influence of potentially extreme weights, we used stabilized weights ${ }^{3}$, defined as $\widehat{w_{l}}=\widehat{P}\left(A=a_{i}\right) /$ $\widehat{P}\left(A=a_{i} \mid C=c_{i}\right)=\widehat{P}\left(A=a_{i}\right) \widehat{w_{l}^{*}}$.

Our choice of weights as described above corresponds to the ATE for the overall cohort, either the US RPDR or the UK CPRD, with a covariate composition as detailed in Table 2 of the main text.

Assessment of covariate balance between treatment groups. The achieved balance for age is presented in Extended Data Fig. 10, while overall covariate balance is summarized in Extended Data Fig. 11. In the estimation of treatment effects in strata of age, of sex and of BMI, we conducted separate analyses in each subgroup of patients ${ }^{57}$ and estimated the IPTW weights for each stratum of the covariate.

Covariate missingness. In both cohorts, we quantified missingness rates for each covariate (see notes to Table 2), and missing values in these variables were treated as a separate category. For each categorical variable affected by missingness in the US RPDR (i.e., BMI and HbA1C), a binary indicator was added in the propensity score model. Similarly, for each categorical variable affected by missingness in the UK CPDR (i.e., BMI, HbA1C, smoking status), a binary indicator was added in the propensity score model. 
medRxiv preprint doi: https://doi.org/10.1101/2021.08.10.21261747; this version posted August 12, 2021. The copyright holder for this preprint (which was not certified by peer review) is the author/funder, who has granted medRxiv a license to display the preprint in perpetuity.

It is made available under a CC-BY-ND 4.0 International license .

US RPDR. In the RPDR cohort, there were missing values in both the BMI (32\%) and HbA1C (38\%) variables at antidiabetic treatment initiation. Missingness affected sulfonylurea- more than metformininitiators, as $42 \%$ of them were missing BMI information at baseline and 52\% did not have an $\mathrm{HbA} 1 \mathrm{C}$ measure (Table 2). In the propensity score model, we treated missing data as a separate category, for both the baseline BMI and HbA1C variables. Further, we combined the two categories of missing BMI and $\mathrm{BMI}<25$ into one, assuming that the baseline BMI would be more likely to be captured in the medical records if it were $>25$. Additionally, we noted that the effects of missing BMI and BMI $<25$ indicators on treatment assignment were similar, and thus we collapsed the two into one reference category.

UK CPRD. Similarly, sulfonylurea initiators had more missing values than metformin initiators in the CPRD cohort, as $21 \%, 35 \%$ and $5 \%$ of them were missing BMI, HbA1C and smoking status information at baseline, respectively.

\section{Statistical analyses}

\section{Estimation of treatment effect on all-cause mortality}

For a single time-to-death outcome, we estimated the Cox proportional hazards model and the nonparametric Kaplan-Meier survival curves for both inverse-probability-of-treatment-weighted treatment arms. The latter model allows to estimate robustly the time-varying causal survival curves ${ }^{58}$, while the former model provides a one-number summary of the treatment effect through a fixed hazard ratio. We used the Cox proportional hazards model

$$
h^{1}(t)=h^{0}(t) \exp (\beta)
$$

assuming that the hazards of death are proportional in two counterfactual worlds, a world where everyone receives metformin, $h^{1}(t)$, and a world where everyone receives sulfonylureas, $h^{0}(t)$, with a proportionality factor $H R=\exp (\beta)$.

Technically, to estimate the effect of metformin on all-cause mortality, we considered the same causal framework as for the competing risks (detailed below) but only for a single outcome, time-to-death. This means that both our analyses rely on the same causal assumptions $(A 1),(A 2)$, and $(A 3)$, and the assumption of independent censoring. Practically, for both cases we used our R package, causalCmprsk, to estimate the causal survival curves. ${ }^{59}$ 
medRxiv preprint doi: https://doi.org/10.1101/2021.08.10.21261747; this version posted August 12, 2021. The copyright holder for this preprint (which was not certified by peer review) is the author/funder, who has granted medRxiv a license to display the preprint in perpetuity.

It is made available under a CC-BY-ND 4.0 International license .

To allow some time for the antidiabetic drug to have an effect, we introduced a one-year lag: in our trial emulations, the follow-up started a year after treatment initiation. Therefore, the effect measures we estimated are to be interpreted for the cohort of patients who survive at least a year post baseline.

\section{Estimation of treatment effect on dementia in the presence of competing death}

In this section, we provide details on statistical methods used for the estimation of the intention-to-treat effect of metformin versus sulfonylureas on the risk of dementia in the presence of competing death.

To allow some time for the antidiabetic drug to have an effect on dementia, a one-year lag was introduced: in our trial emulations, the follow-up started a year after treatment initiation. Therefore, effect measures are to be interpreted for the cohort of patients who are at risk for both events, dementia and death, a year post baseline. Patients who developed dementia within twelve months post antidiabetic treatment initiation may well have had cognitive problems at baseline and would likely have not met the eligibility criteria of any randomized clinical trial. Similarly, patients who died in the first year likely had a high mortality risk and would not be included in an actual clinical trial.

\section{1) Notation}

Let $T$ denote the time from treatment initiation to dementia onset or death (without prior dementia), whichever comes first. Let $E$ denote the indicator of the type of event, with $E=1$ if $T$ corresponds to dementia onset, and $E=2$ if $T$ corresponds to death. If neither dementia nor death is observed during the follow-up period, then $T$ is censored by the time to the last visit, and $E=0$. It is important to note that we only consider here death without having prior dementia, i.e., the direct transition to death that does not go through the dementia state (see Extended Data Fig. 12). Dementia and death (without prior dementia) are two mutually exclusive outcomes, and it is assumed that treatment can potentially affect both. The observed data are assumed to be $n$ independent observations of the quadruplet $(T, E, A, C)$, i.e., $\left(t_{i}, e_{i}, a_{i}, c_{i}\right)$, for $i=1, \ldots, n$.

\section{2) Assumptions}

Let $\left(T^{a}, E^{a}\right)$, for $a=0,1$ denote the potential outcomes that would be observed if a patient were to receive treatment $a$. Our causal assumptions are the following:

(A1) No unmeasured confounding: treatment assignment $A$ is independent of potential outcomes given $C$, i.e.: 


$$
A \perp\left(T^{a}, E^{a}\right) \mid C, \text { for } a=0,1
$$

\section{(A2) Positivity:}

$$
0<P(A=a \mid C)<1 \text {, for } a=0,1
$$

(A3) SUTVA (Stable Unit Treatment Value Assumption): the outcome of every patient does not depend on the treatment of others (non-interference), and the outcome does not depend on the way a treatment was assigned (consistency).

Additionally, we assume that given $A$, the time to the last visit (censoring time) is independent of the outcome $(T, E)$.

\section{3) Measures of treatment effect}

Let $h_{k}^{a}(t)(a=0,1 ; k=1,2)$ be the single-world cause-specific hazards of transitioning to states 1 or 2 in a world corresponding to treatment $a=0,1$ (see Extended Data Fig. 12). This quantity is defined as follows:

$$
h_{k}^{a}(t)=\lim _{\Delta t \rightarrow 0} \frac{1}{\Delta t} P\left(t \leq T^{a}<t+\Delta t, E^{a}=k \mid T^{a} \geq t\right), \text { for } k=1,2 .
$$

The single-world cumulative incidence functions (CIF) are defined by:

$$
C I F_{a}(t, k)=E\left[I_{\left(T^{a} \leq t, E^{a}=k\right)}\right]=P\left(T^{a} \leq t, E^{a}=k\right)=\int_{0}^{t} S_{a}(s) h_{k}^{a}(s) d s, \text { for } k=1,2
$$

where $S_{a}(t)$ is an overall survival function in the counterfactual world corresponding to treatment a, i.e, $S_{a}(t)$ is the probability of not having any event, neither dementia nor death, by time $t: S_{a}(t)=$ $\exp \left\{-\int_{0}^{t} h_{1}^{a}(s) d s-\int_{0}^{t} h_{2}^{a}(s) d s\right\}=S_{1}^{a}(t) S_{2}^{a}(t)$, where $S_{1}^{a}(t)=\exp \left\{-\int_{0}^{t} h_{1}^{a}(s) d s\right\}$ and $S_{2}^{a}(t)=\exp \left\{-\int_{0}^{t} h_{2}^{a}(s) d s\right\}$.

From [1], it is clear that the risk of dementia, denoted by $\operatorname{CIF}_{a}(t, 1)(a=0,1)$, depends on the causespecific hazard of death, denoted by $h_{2}^{a}(t)(a=0,1)$, through the overall survival function $S_{a}(t)(a=$ $0,1)$. The function $C I F_{a}(t, k)(a=0,1 ; k=1,2)$, which is often called risk $k^{61}$, represents the absolute probability of failing from cause $k=1,2$ by time $t$, in the counterfactual world corresponding to treatment $a=0,1$. 
We emphasize that a risk function, $\operatorname{CIF}_{a}(t, k)(a=0,1 ; k=1,2)$, is much more intuitive for interpretation and communication of findings than a hazard (or rate) parameter, $h_{k}^{a}(t)(a=0,1 ; k=$ $1,2)$. The latter represents an instantaneous probability of failure from cause $k$ at time $t$, conditional on still being at risk at time $t$, in the counterfactual world corresponding to treatment $a=0,1^{60,61}$.

In our emulations of a target trial, we used the two following measures of treatment effect.

a) The hazard ratios for both events are defined by:

$$
H R_{k}(t)=\frac{h_{k}^{1}(t)}{h_{k}^{0}(t)}, \text { for } k=1,2
$$

Notice that here the ratios $H R_{k}(t)(k=1,2)$ can depend on time $t$, since they are defined in complete generality regardless of the statistical model used for estimation of hazard functions $h_{k}^{a}(t)(a=0,1 ; k=$ $1,2)$. However, it is often assumed that $H_{k}(t)(k=1,2)$ are time-invariant and equal to a constant value $H_{k}(k=1,2)$ for all time points $t$, which follows from assuming the Cox proportional hazards model (PH) for $h_{k}^{a}(t)(a=0,1 ; k=1,2)$, as defined by [2] below. The PH assumption cannot be tested in general, since only one potential outcome is observed for every person. However, it can be tested or checked graphically under causal assumptions $(A 1),(A 2)$, and $(A 3)$ listed above.

Although the time-invariant hazard ratios $H_{k}(k=1,2)$ are problematic parameters for causal inference due to their non-collapsibility ${ }^{62-64}$, they are traditionally used as effect measures in the medical literature. To conform with previous research on antidiabetic drugs and their effects on dementia, we thus considered hazard ratios in our target trial emulations as well.

b) The risk difference functions are defined by:

$$
R D(t, k)=E\left[I_{\left(T^{1} \leq t, E^{1}=k\right)}\right]-E\left[I_{\left(T^{0} \leq t, E^{0}=k\right)}\right]=C I F_{1}(t, k)-C I F_{0}(t, k), \text { for } k=1,2
$$

$R D(t, k)(k=1,2)$ is the average treatment effect (ATE) on getting outcome $k$ by time $t$. We chose the risk difference as a summary of a treatment effect, but other options, e.g., risk ratios, could be considered as well.

\section{4) Estimation}


Assuming the proportional hazards model. Under assumptions $(A 1),(A 2)$, and $(A 3)$, we checked graphically that both $H R_{k}(t)(k=1,2)$ do not depend on $t$. This allowed us to use the Cox PH models for both transitions:

$$
h_{k}^{0}(t)=h_{0 k}(t) ; h_{k}^{1}(t)=h_{0 k}(t) \exp \left(\beta_{k}\right), \text { for } k=1,2
$$

Model [2] assumes that cause-specific hazards for dementia are proportional in two counterfactual worlds, a world where everyone receives metformin and a world where everyone receives sulfonylureas, with a proportionality factor $H R_{1}=\exp \left(\beta_{1}\right)$. Similarly, according to model [2], the hazards $h_{2}^{1}(t)$ and $h_{2}^{0}(t)$ corresponding to the direct transition to death (without prior dementia) are assumed to be proportional with a proportionality factor $H R_{2}=\exp \left(\beta_{2}\right)$.

Details on the estimation procedure for treatment effect measures. The estimators of $H R_{k}$, $C I F_{a}(t, k)(a=0,1 ; k=1,2)$, and $R D(t, k)(k=1,2)$ are obtained by plugging in the estimators of $\beta_{k}$ and $h_{0 k}(t)(k=1,2)$. The estimator of $\beta_{k}(k=1,2)$ is the solution of a weighted version of the Cox score equation (Cox, 1972) and the estimator of the cumulative baseline hazard function $H_{0 k}(t)=$ $\int_{0}^{t} h_{0 k}(s) d s(k=1,2)$ is a weighted version of the Breslow-type estimator with a plugged-in $\widehat{\beta_{k}} 12$ The estimator of $H R_{k}$ is $\widehat{H R_{k}}=\exp \left(\widehat{\beta_{k}}\right)(k=1,2)$ and $R D(t, k)$ is given by: $\widehat{R D}(t, k)=\widehat{C I F_{1}}(t, k)-$ $\widehat{C I F_{0}}(t, k)$, for $k=1,2$ (for more details, see ref. 59).

$$
\sum_{i=1}^{n} \widehat{w}_{l} I\left(e_{i}=k\right)\left[a_{i}-\frac{\sum_{j=1}^{n} \widehat{w_{J}} a_{j} \exp \left(\beta_{k} a_{j}\right) I\left(t_{j} \geq t_{i}\right)}{\sum_{j=1}^{n} \widehat{w_{J}} \exp \left(\beta_{k} a_{j}\right) I\left(t_{j} \geq t_{i}\right)}\right]=0
$$

where $\widehat{w}_{l}$ are the weights emulating baseline randomization defined above.

a) The estimator of the cumulative baseline hazard function $H_{0 k}(t)=\int_{0}^{t} h_{0 k}(s) d s(k=1,2)$ is a weighted version of the Breslow-type estimator with a plugged-in $\widehat{\beta_{k}} 12$ :

$$
\widehat{H_{0 k}}(t) \sum_{i: e_{i}=k} \frac{\widehat{w_{l}} I\left(t_{i} \leq t\right)}{\sum_{j} \widehat{w_{J}} \exp \left(\widehat{\beta_{k}} a_{j}\right) I\left(t_{i} \leq t_{j}\right)}
$$

b) The estimator of $H R_{k}$ is $\widehat{H R_{k}}=\exp \left(\widehat{\beta_{k}}\right)(k=1,2)$. 
c) The estimator of $C I F_{a}(t, k)$ is given by:

$$
\widehat{\operatorname{CIF}_{a}}(t, k)=\sum_{i: e_{i}=k, t_{i} \leq t} \frac{\widehat{w_{l}} \exp \left(-\widehat{H_{01}}\left(t_{i}\right) e^{\widehat{\beta_{1}} a}-\widehat{H_{02}}\left(t_{i}\right) e^{\widehat{\beta_{2}} a}\right)}{\sum_{j} \widehat{w_{J}} \exp \left(\widehat{\beta_{k}} a_{j}\right) I\left(t_{i} \leq t_{j}\right)}, \text { for } a=0,1 ; k=1,2
$$

d) The estimator of $R D(t, k)$ is given by: $\widehat{R D}(t, k)=\widehat{C I F_{1}}(t, k)-\widehat{C I F_{0}}(t, k)$, for $k=1,2$.

We estimated the $95 \%$ confidence intervals for all the parameters using the Bayesian bootstrap ${ }^{65}$, where a bootstrap sample comprises an original cohort, but every subject's contribution is reweighted with a random bootstrap weight $w_{i}^{b s}=V_{i} / \bar{V}$ for $i=1, \ldots, n$, where $V_{1}, \ldots, V_{n} \sim \operatorname{Exp}(1)$ are independent, and $\bar{V}=\frac{1}{n} \sum_{i=1}^{n} V_{i}$.

For each bootstrap replication, we repeated the steps of fitting the logistic regression to obtain the balancing weights, and the steps a)-e), in order to obtain estimates for all the parameters, i.e., $\beta_{k}, H_{0 k}(t)$, $C I F_{a}(t, k)(a=0,1 ; k=1,2)$, and $R D(t, k)(k=1,2)$ for each of the bootstrap samples.

The Bayesian bootstrap is a better and more stable alternative to the standard bootstrap in survival data, since it does not have a problem of ties, and since the risk sets in all Bayesian bootstrap replications change at the same time points as in the original sample. The $95 \%$ confidence interval was obtained as 2.5th and 97.5th percentiles from the distributions of bootstrap estimates. For the time-dependent parameters such as $C I F_{a}(t, k)(a=0,1 ; k=1,2)$ or $R D(t, k)(k=1,2)$, the confidence intervals were obtained pointwise for every $t$. In our target trial emulations, we used 500 bootstrap replications.

Checking a proportional hazards assumption using a nonparametric framework. Under assumptions (A1), (A2), and (A3), we checked graphically that both $H R_{k}(t)(k=1,2)$ do not depend on $t$. We did this by using the nonparametric framework which does not assume any structure for the hazard functions $h_{k}^{a}(t)(a=0,1 ; k=1,2)$.

In the all-cause mortality analyses, we tested the PH assumption using other approaches as well. These include the global test based on Schoenfeld residuals and a log-rank test. The tests indicated that the proportional hazards assumption was not violated in the US RPDR cohort. However, given that the graphical check revealed violation of the PH assumption in the UK CPRD cohort, we used nonparametric estimates of causal survival curves based on IPTW Kaplan-Meier estimates.

\section{Systems pharmacological analysis of metformin and sulfonylureas in human neural cells}


medRxiv preprint doi: https://doi.org/10.1101/2021.08.10.21261747; this version posted August 12, 2021. The copyright holder for this preprint (which was not certified by peer review) is the author/funder, who has granted medRxiv a license to display the preprint in perpetuity.

It is made available under a CC-BY-ND 4.0 International license.

Both $10 \mu \mathrm{M}$ and $40 \mu \mathrm{M}$ of metformin or glyburide were added to differentiated human ReNcell VM neural cultures for 72 hours (drugs were refreshed at 48 hours). At 72 hours, RNA was isolated using RNease mini kit (catalog \#74104, Qiagen, Germantown, MD). RNA quality was verified using Bioanalyzer (Agilent, 2100 Bioanalyzer Systems); all samples scored RINs of > 9.0. RNA sequencing library preparation was performed with the TruSeq Stranded mRNA Library Prep Kit (Illumina) following the manufacturer's protocol at half reaction volume. Input for each sample consisted of 500ng of RNA and 5ul of 1:500 diluted ERCC spike-in mix (Ambion). Libraries were amplified for 12 cycles during the final amplification step. Libraries were sequenced on a NextSeq RNA sequencer (Illumina). Raw sequencing reads were aligned against the hg38 (build 94) reference and quantified using the bcbio-nextgen RNA-seq analysis pipeline ${ }^{66}$. Differential gene expression between compound-treated samples and DMSO controls was performed by the R package $e d g e R$ version $3.26 .5^{67}$. Genes were subsequently sorted by the resulting log-fold change values and queried against canonical pathways in the Molecular Signatures Database ${ }^{68}$ using Gene Set Enrichment Analysis ${ }^{69}$. Secreted genes were identified by detection in human CSF proteome $^{70}$. The differential expression analysis of the human SPP1 gene in gene expression profiles of AD brains from AMP-AD datasets was conducted as follows. The aligned RNAseq data was provided as input to differential gene expression analysis contrasting advanced Braak stages (Braak V, VI) versus controls (Braak 0, I, II) in the ROSMAP, Mount Sinai Brain Bank and Mayo Brain Bank cohorts as described elsewhere ${ }^{70,71}$. Differentiated human ReNcell VM neural cells were grown for various times in the presence of $10 \mu \mathrm{M}$ or $40 \mu \mathrm{M}$ of metformin or glyburide. At prespecified time points, the medium was withdrawn, and human SPP1 protein levels were analyzed by ELISA (ThermoFisher). The results were analyzed using ANOVA with drug and concentrations as covariates with post-hoc Tukey tests used to test for significant findings.

\section{Data availability}

US RPDR. Researchers can obtain an anonymized version of the study dataset from the authors upon request and completion of the MGB Health data use agreement for the use of RPDR data. This agreement ensures the privacy of MGB patients and compliance with US regulatory standards and has been approved by the MGB IRB.

UK CPRD. According to the UK Data Protection Act, information governance restrictions (to protect patient confidentiality) prevent data sharing via public deposition. Therefore, CPRD data that support the findings of this study are not publicly available. Data extracts can be requested by applying to the Clinical Practice Research Datalink for data spanning the years 2000 to 2018 (https://www.cprd.com). The code to process the data is available from the authors upon request. 
medRxiv preprint doi: https://doi.org/10.1101/2021.08.10.21261747; this version posted August 12, 2021. The copyright holder for this preprint (which was not certified by peer review) is the author/funder, who has granted medRxiv a license to display the preprint in perpetuity.

It is made available under a CC-BY-ND 4.0 International license .

Metformin/Glyburide RNA-seq. https://www.synapse.org/\#!Synapse:syn22213067

\section{Code availability}

The R package, causalCmprsk, developed for the competing risks analysis is available at $\mathrm{CRAN}^{59}$. 


\section{EXTENDED DATA FIGURES}

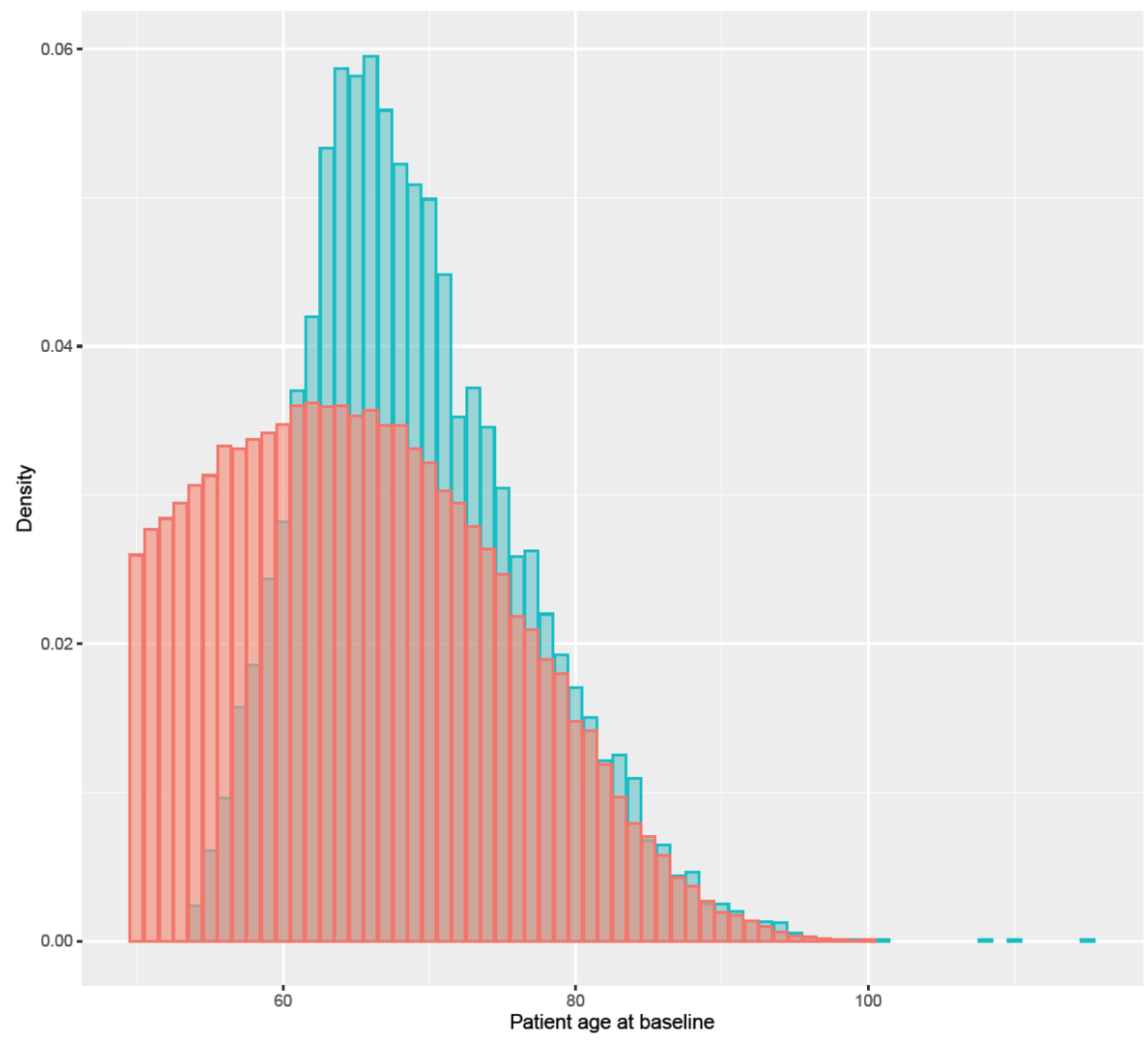

Extended Data Fig. 1 | Density curves for patient age at baseline. Both the US RPDR (blue) and the UK CPRD cohorts (salmon) are graphed. 


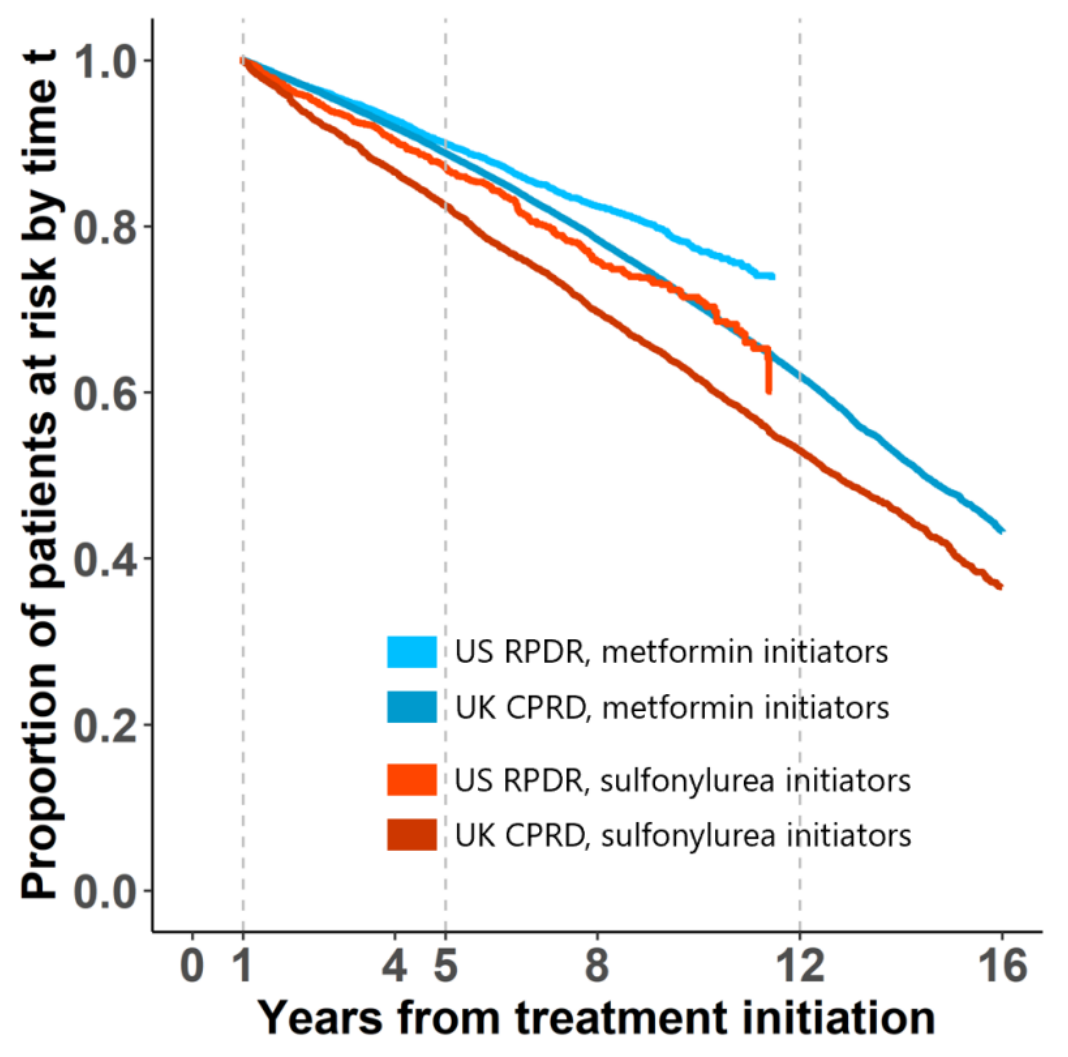

Extended Data Fig. 2 | Proportion of patients at risk over time among metformin and sulfonylurea initiators. Both the US RPDR and the UK CPRD cohorts are graphed. 
a

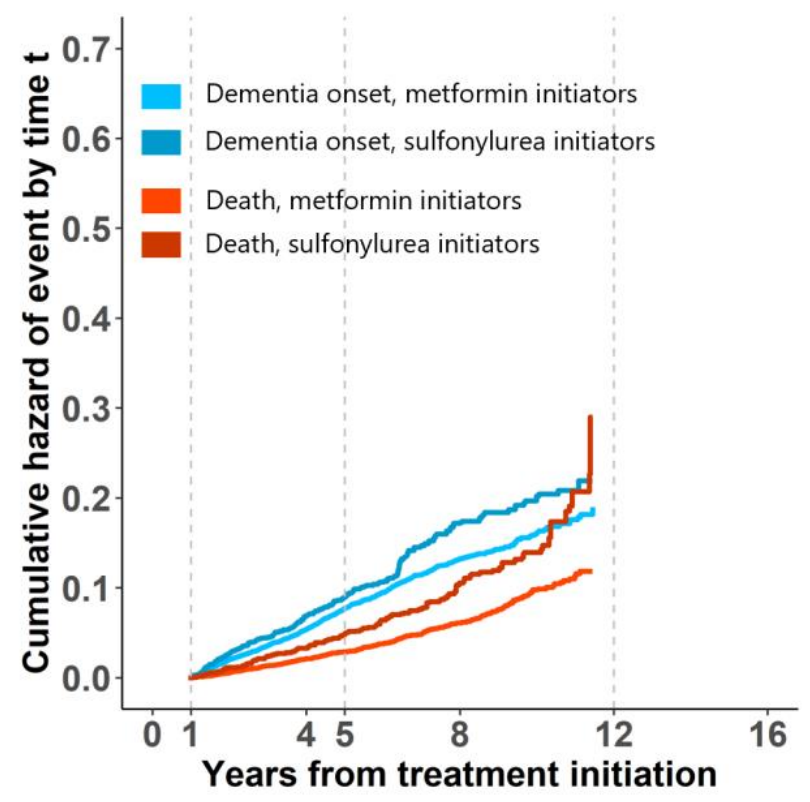

b

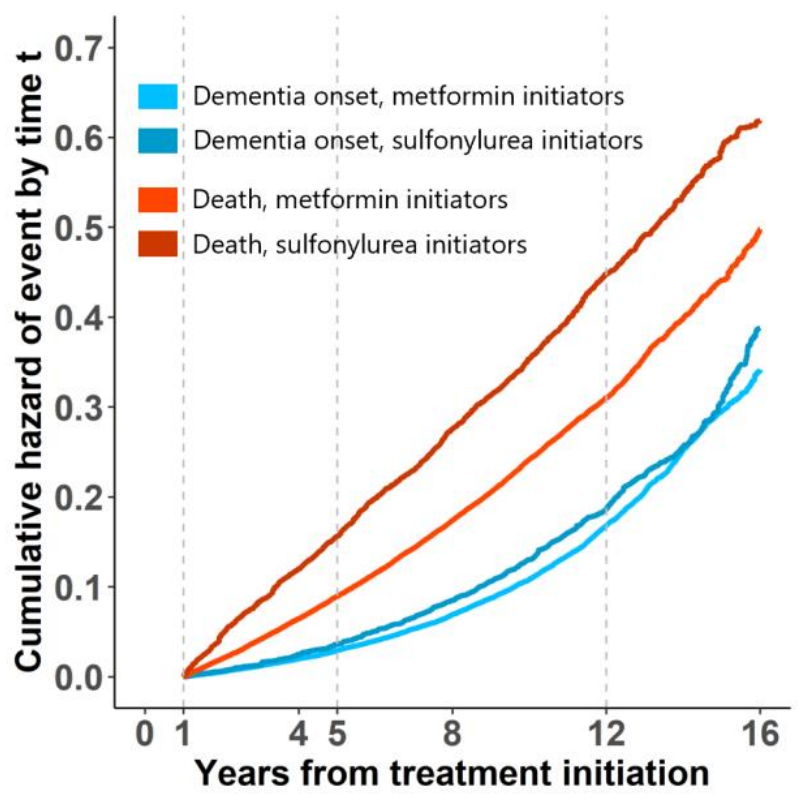

Extended Data Fig. 3 | Absolute cumulative hazard of dementia onset and death. Cumulative risk curves in the (a) US RPDR and (b) UK CPRD cohorts for metformin and sulfonylurea initiators. 
a

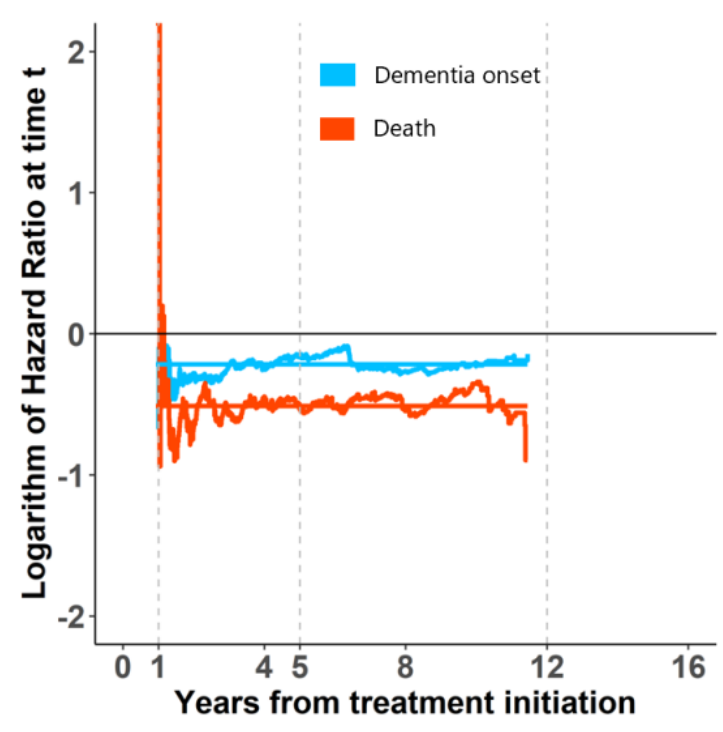

b

$\underline{\text { UK CPRD }}$

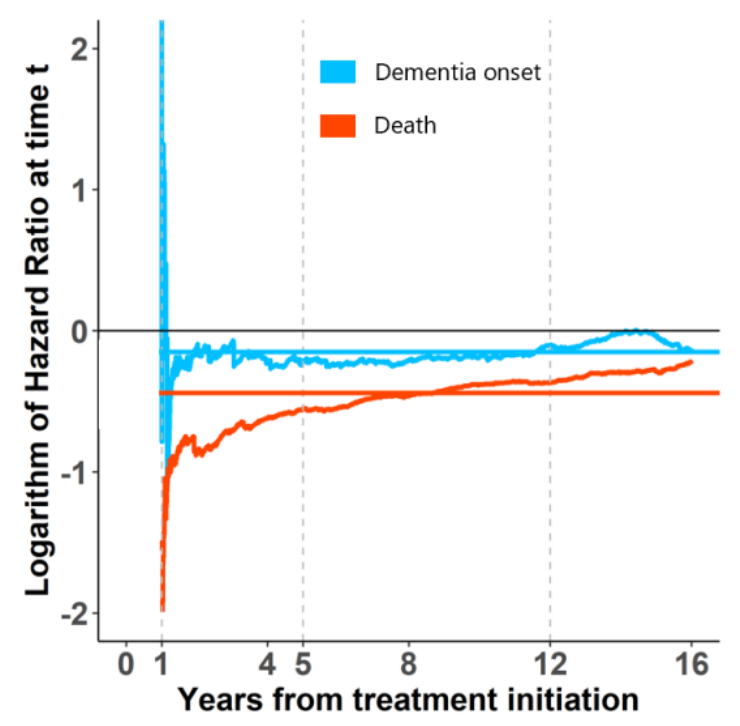

Extended Data Fig. 4 | Comparison of the log of hazard ratios estimated via the Cox PH model vs. the nonparametric approach, for both dementia onset and death. (a) US RPDR and (b) UK CPRD cohorts, metformin vs. sulfonylureas (reference). 
a

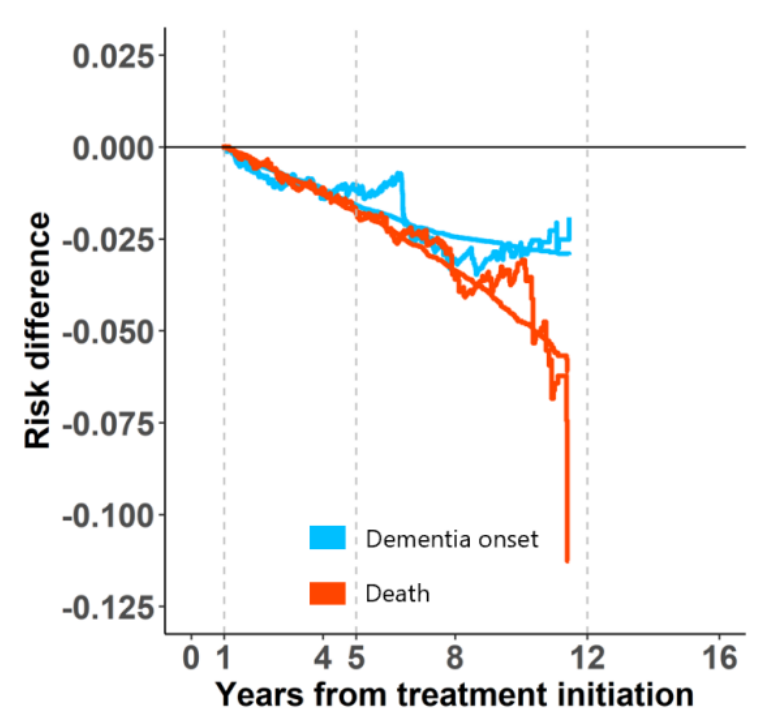

b

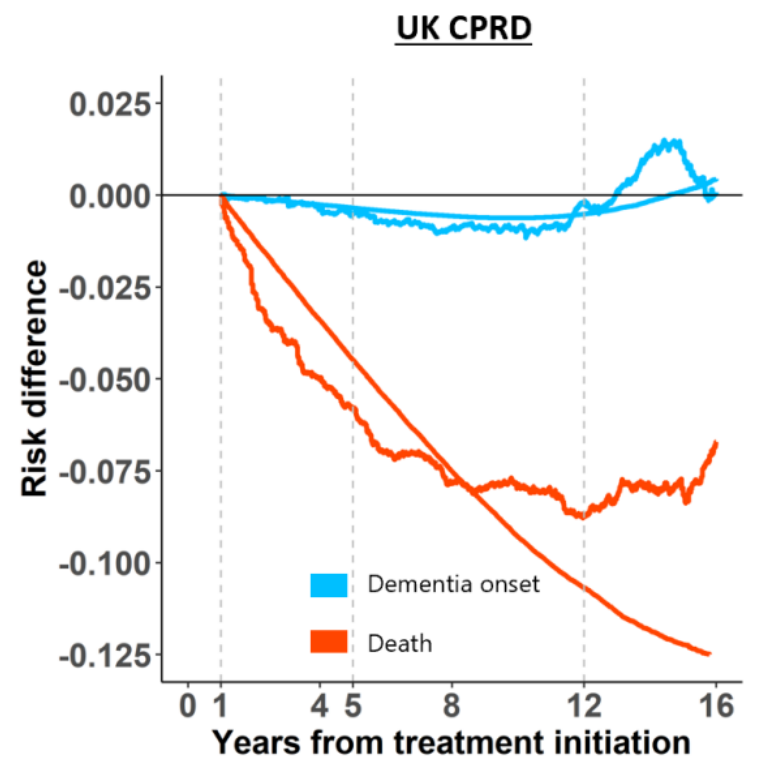

\section{Extended Data Fig. 5 | Risk differences between metformin and sulfonylureas for two competing} outcomes, dementia onset and death. Estimates from a Cox PH model and a nonparametric approach in the (a) US RPDR and (b) UK CPRD cohorts. 
a

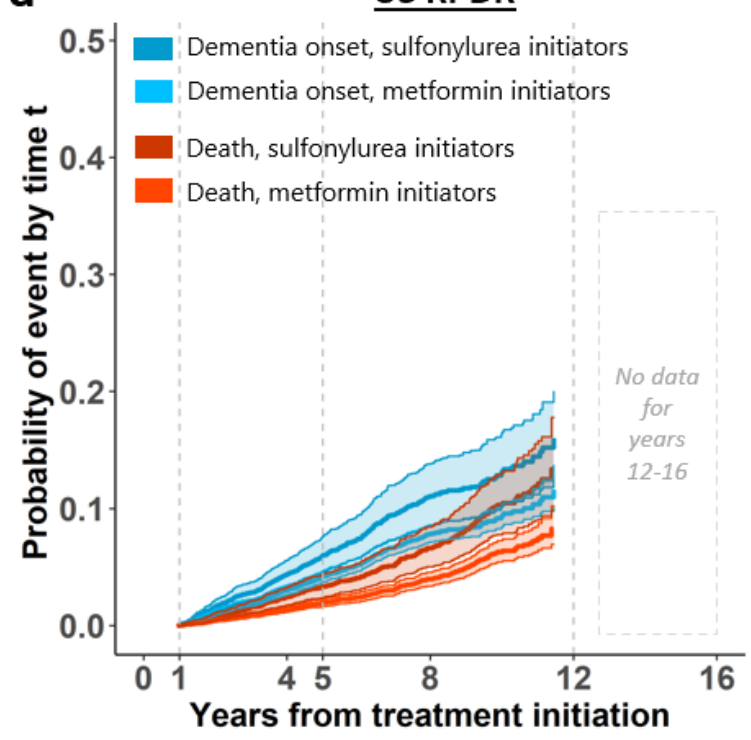

C

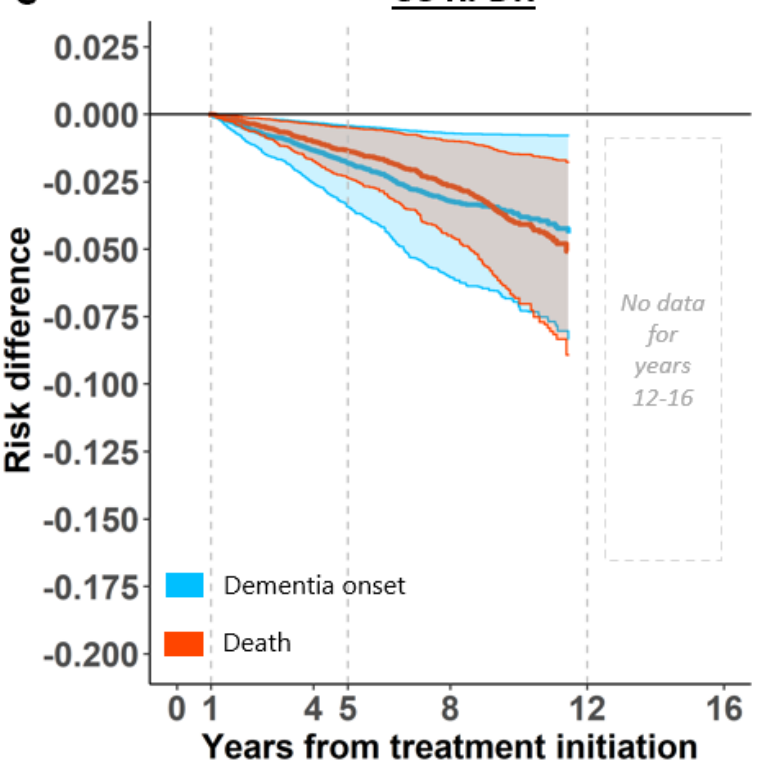

b

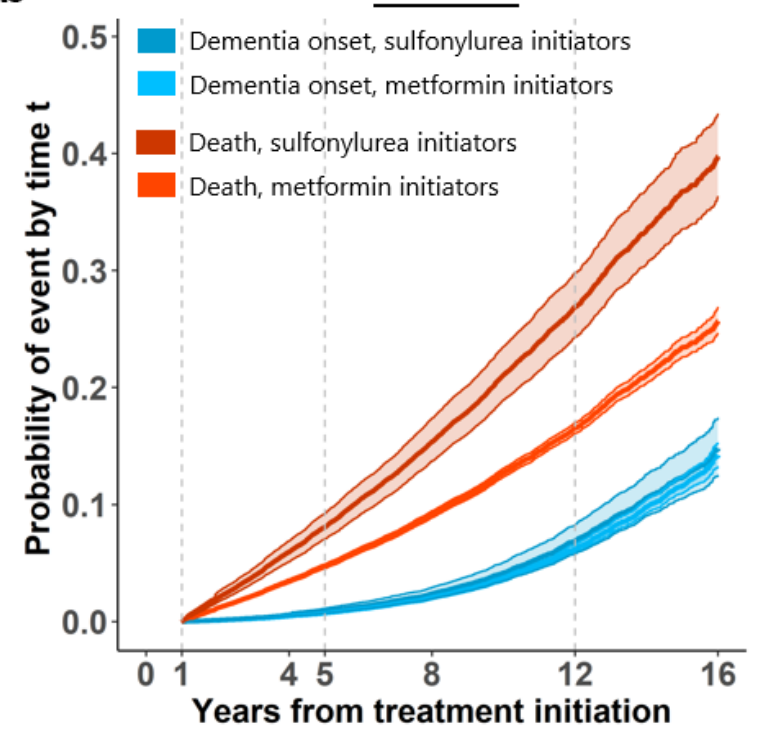

d

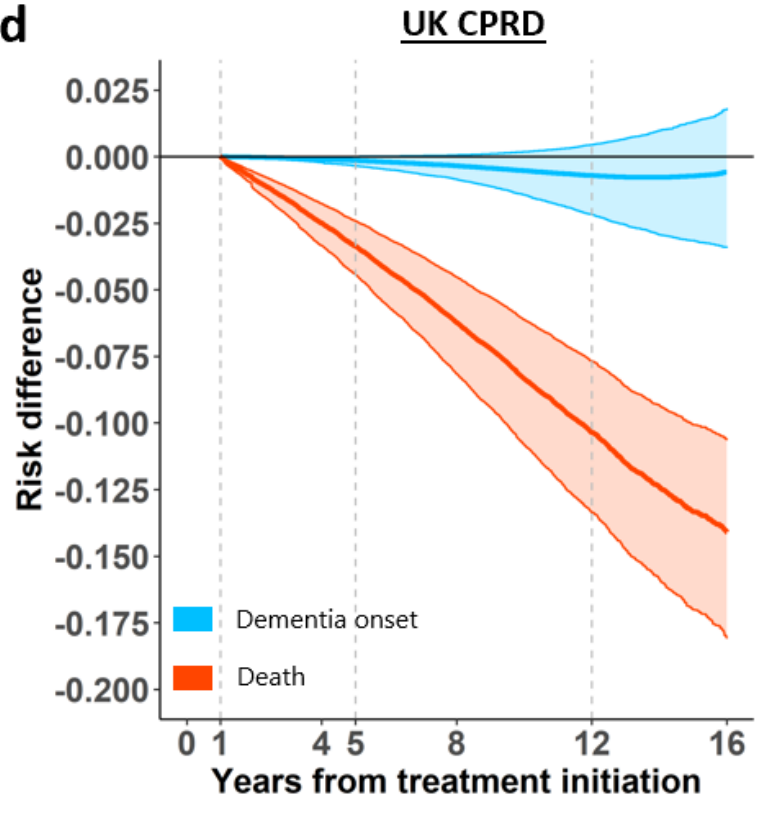

Extended Data Fig. 6 | Results of the competing risks analyses in the stratum of patients of aged $\leq$

70 at baseline. CIF curves for dementia onset and death in the (a) US RPDR and (b) UK CPRD cohorts. Risk differences between metformin and sulfonylureas (reference) in dementia onset and in death in the (c) US RPDR and (d) UK CPRD cohorts. 
medRxiv preprint doi: https://doi.org/10.1101/2021.08.10.21261747; this version posted August 12, 2021. The copyright holder for this preprint (which was not certified by peer review) is the author/funder, who has granted medRxiv a license to display the preprint in perpetuity.

It is made available under a CC-BY-ND 4.0 International license.

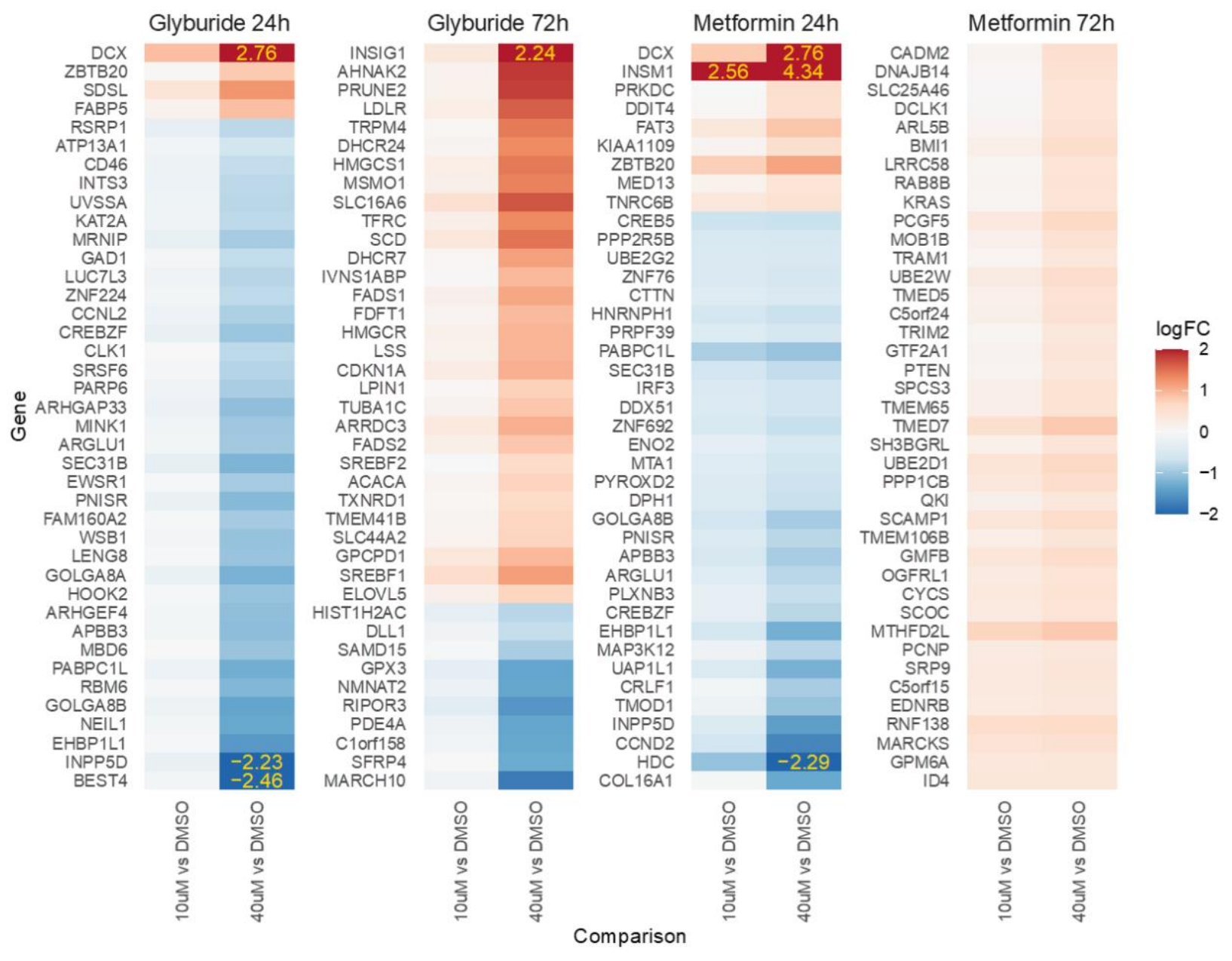

Extended Data Fig. 7 | Full list of genes with dose-dependent changes in expression for metformin and glyburide. Drugs treated differentiated human neural ReNcells at two concentrations (10 or $40 \mu \mathrm{M})$ for either $24 \mathrm{~h}$ or $72 \mathrm{~h}$. 


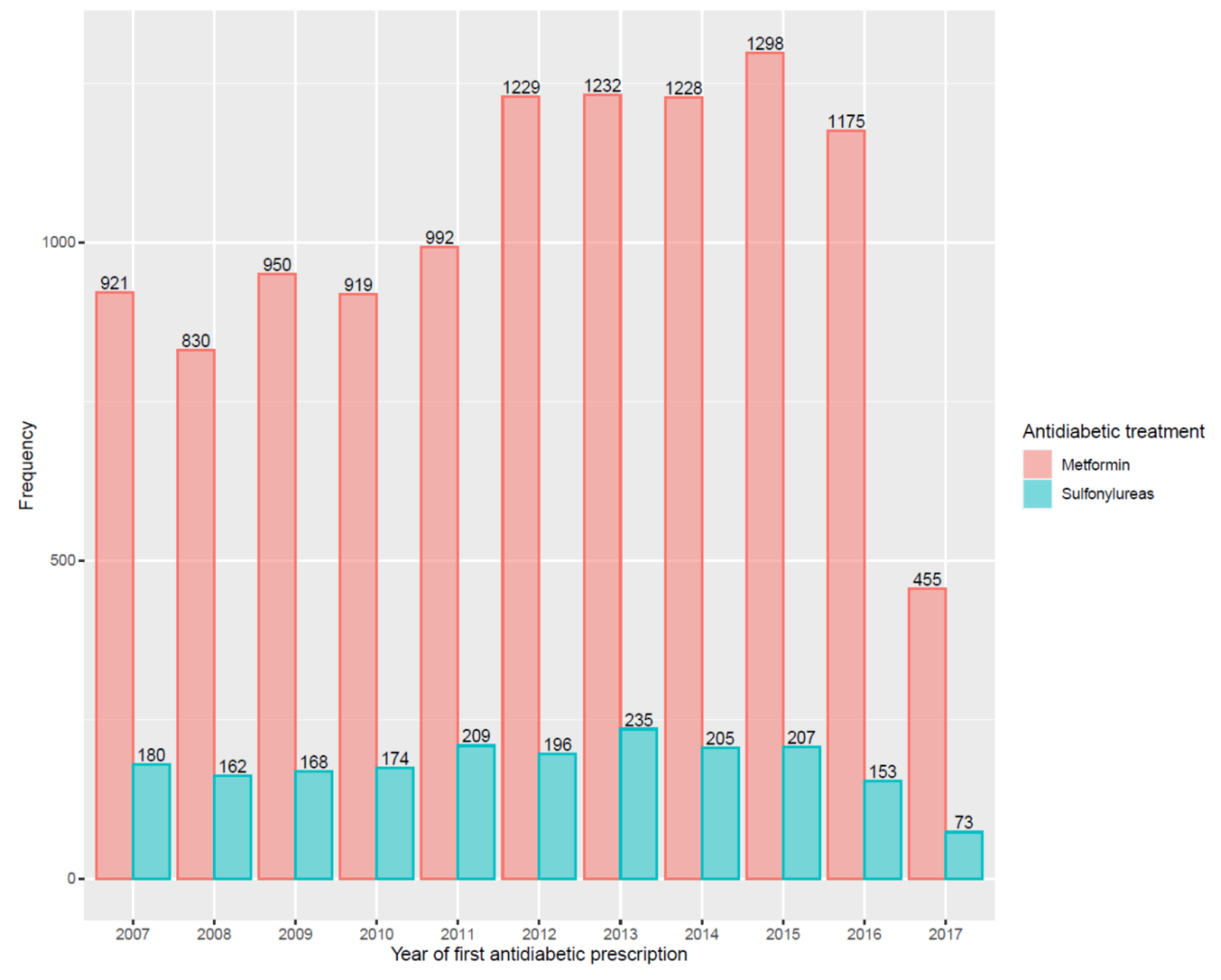

Extended Data Fig. 8 | Number of new prescriptions for metformin and sulfonylureas per year in the US RPDR. 


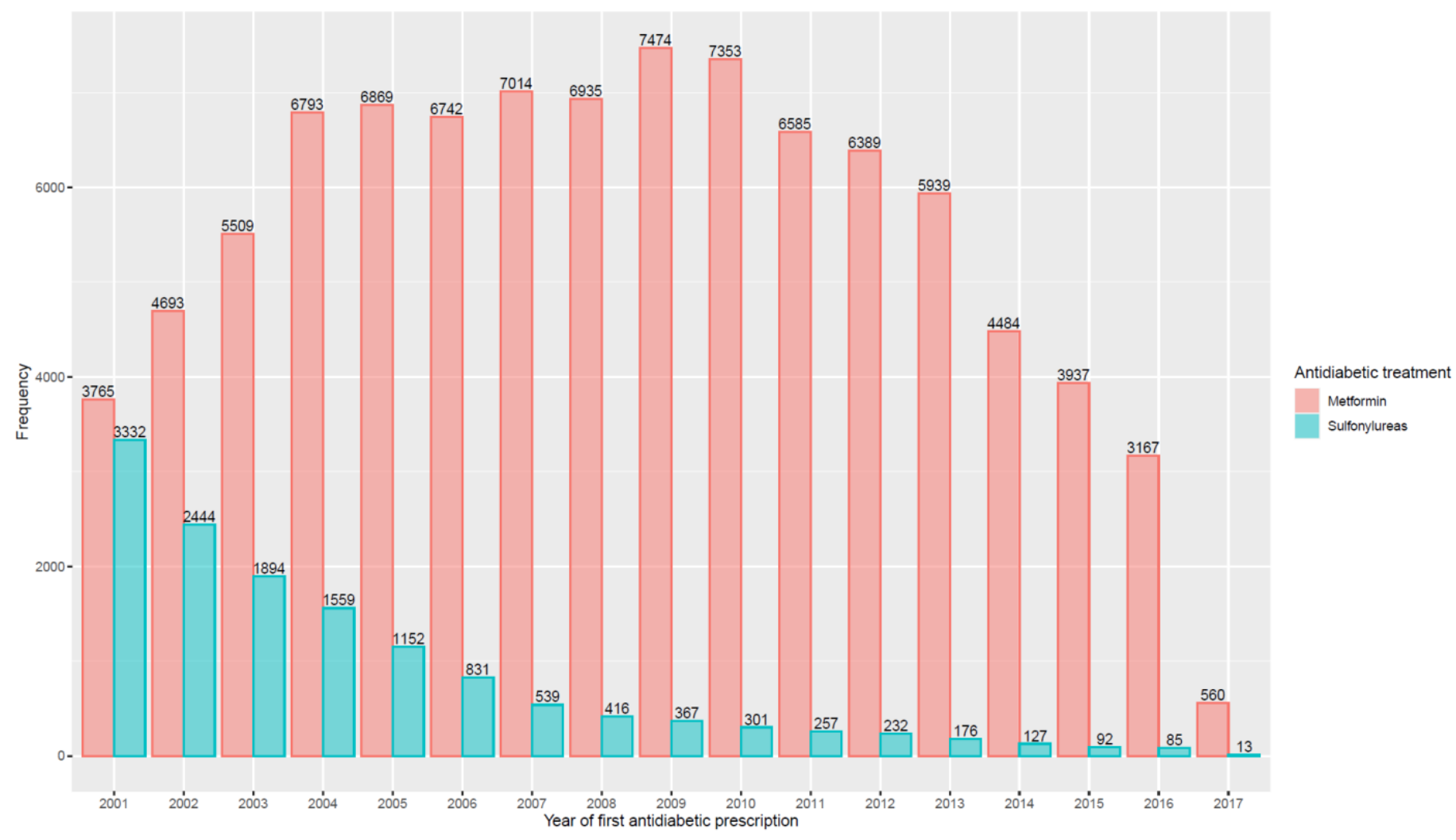

Extended Data Fig. 9 | Number of new prescriptions for metformin and sulfonylureas per year in the UK CPRD. 
medRxiv preprint doi: https://doi.org/10.1101/2021.08.10.21261747; this version posted August 12, 2021. The copyright holder for this preprint (which was not certified by peer review) is the author/funder, who has granted medRxiv a license to display the preprint in perpetuity. It is made available under a CC-BY-ND 4.0 International license.
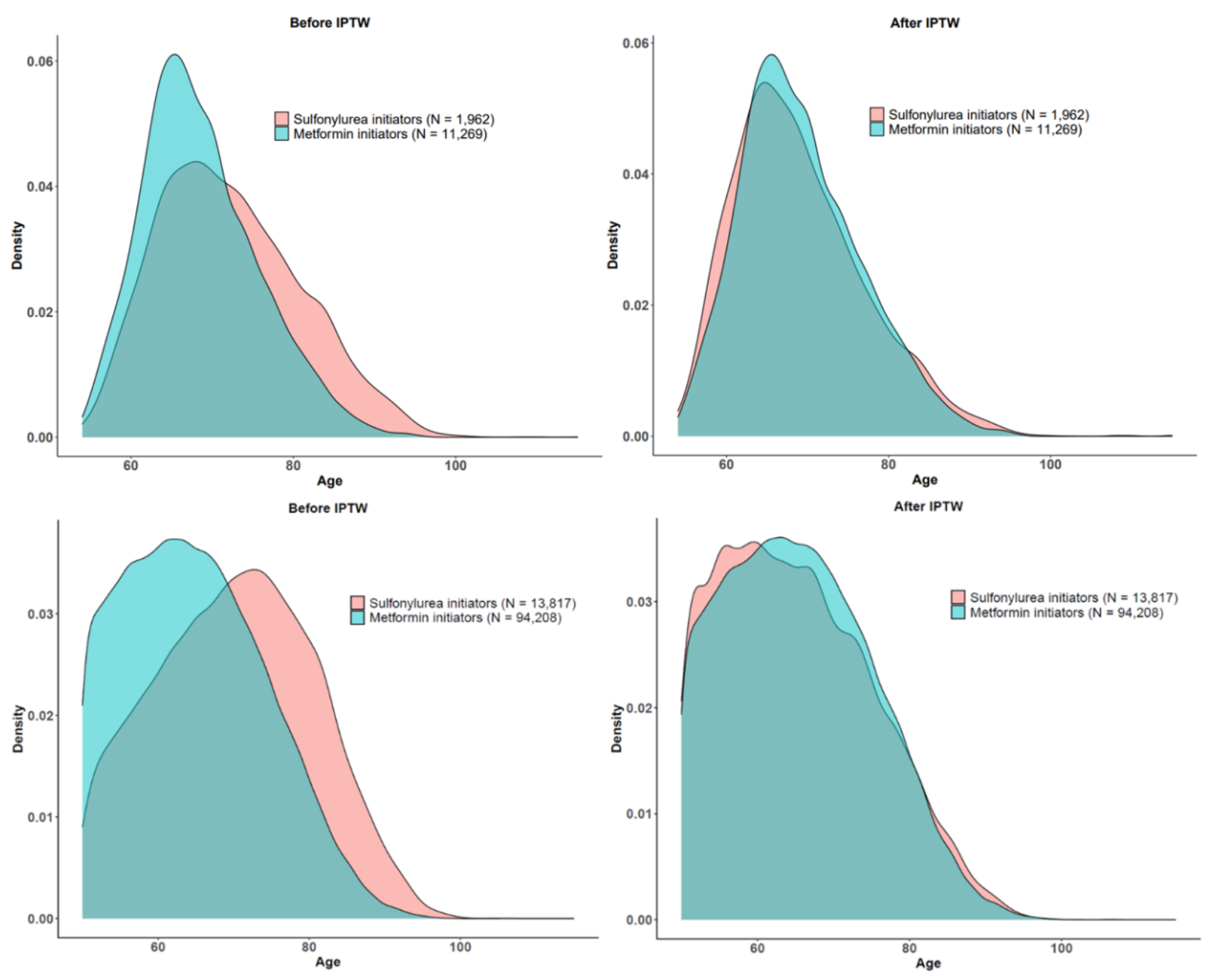

Extended Data Fig. 10 | Density curves for patient age at baseline, stratified by treatment group, before and after IPTW. (a) US RPDR cohort. (b) UK CPRD cohort. 
a

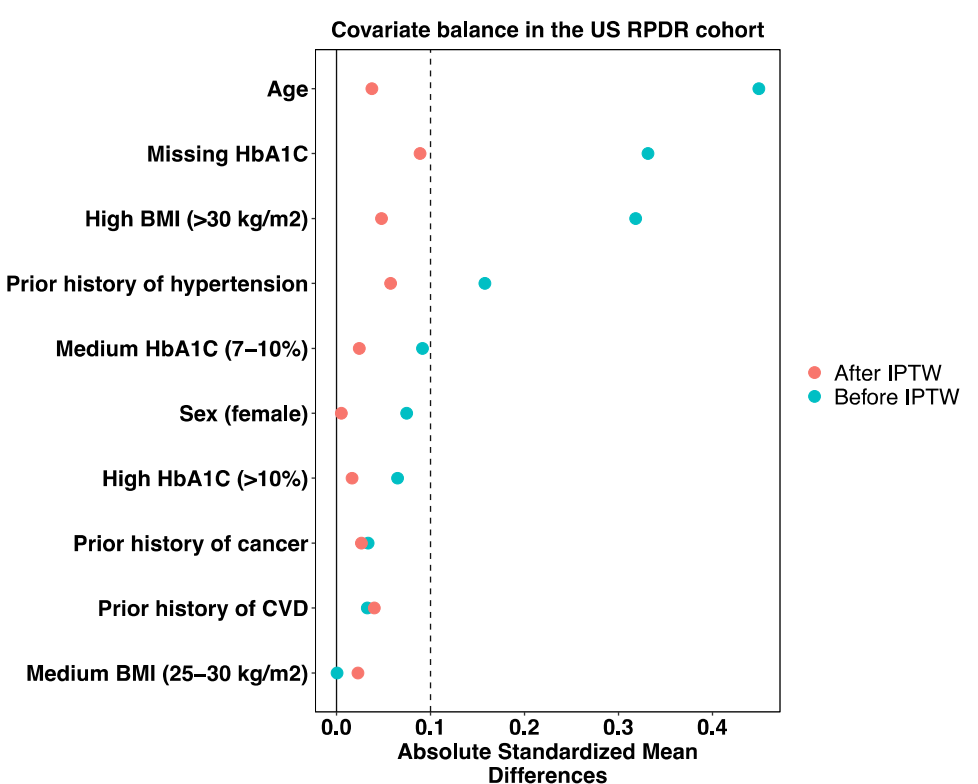

b

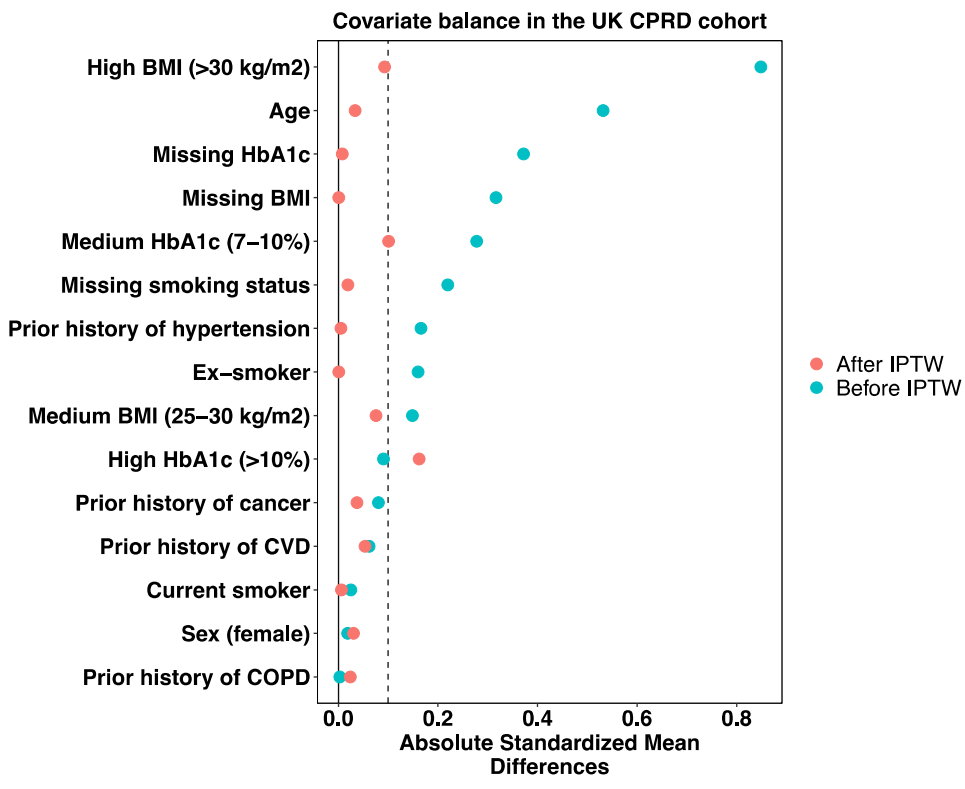

Extended Data Fig. 11 | Overall covariate balance before and after IPTW. (a) US RPDR cohort. (b)

UK CPRD cohort. The standardized mean difference ${ }^{72}$ is a measure of distance between two group means (for metformin and sulfonylurea initiators) in terms of one or more variables (definitions of standardized mean differences for both binary and continuous covariates were adopted from previous work ${ }^{73}$ ). It is often used in practice as a measure of balance of individual covariates before and after propensity score weighting. As it is standardized, comparison across variables on different scales is made possible. 
medRxiv preprint doi: https://doi.org/10.1101/2021.08.10.21261747; this version posted August 12, 2021. The copyright holder for this preprint (which was not certified by peer review) is the author/funder, who has granted medRxiv a license to display the preprint in perpetuity. It is made available under a CC-BY-ND 4.0 International license .

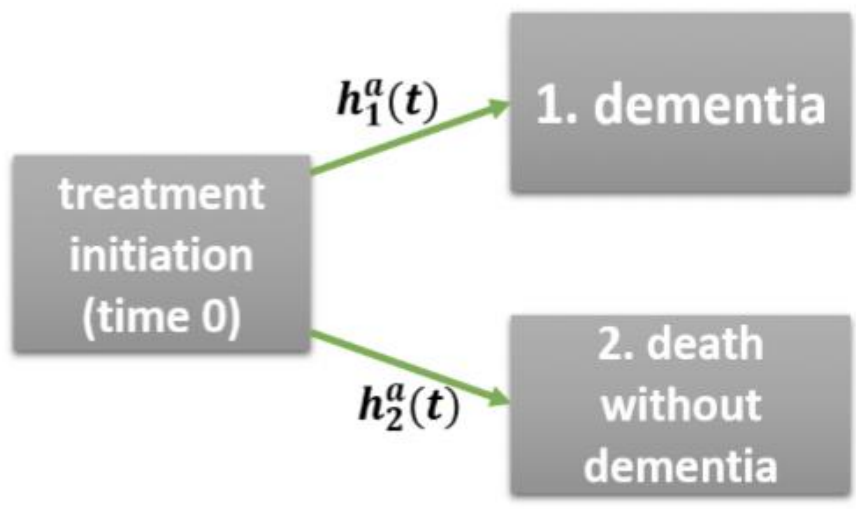

Extended Data Fig. 12 | A single-world competing risks model with two events, namely dementia and death prior to dementia. 
medRxiv preprint doi: https://doi.org/10.1101/2021.08.10.21261747; this version posted August 12, 2021. The copyright holder for this preprint (which was not certified by peer review) is the author/funder, who has granted medRxiv a license to display the preprint in perpetuity. It is made available under a CC-BY-ND 4.0 International license .

\section{EXTENDED DATA TABLES}

Extended Data Table 1 | US CKD diagnosis codes / eGFR criterion table (Excel file).

Extended Data Table 2 | UK CKD diagnosis codes (Excel file). 


\begin{tabular}{llllll}
\hline Outcome event & $\begin{array}{l}\text { Age categories } \\
\text { (year) }\end{array}$ & \multicolumn{4}{l}{ US RPDR } \\
\cline { 3 - 6 } & $\mathrm{N}$ & Cases & HR $(95 \% \mathrm{CI})$ & $P$ \\
\hline All-cause & $\leq 65$ & 4669 & 187 & $0.58(0.40-0.85)$ & 0.005 \\
mortality & $>65$ & 8522 & 562 & $0.58(0.48-0.69)$ & $<0.001$ \\
& $\leq 75$ & 10614 & 478 & $0.53(0.43-0.66)$ & $<0.001$ \\
& $>75$ & 2577 & 271 & $0.63(0.50-0.81)$ & $<0.001$ \\
& & & & & \\
Dementia & $\leq 65$ & 4669 & 273 & $0.57(0.42-0.78)$ & $<0.001$ \\
incidence & $>65$ & 8522 & 837 & $0.96(0.80-1.14)$ & 0.608 \\
& $\leq 75$ & 10614 & 677 & $0.77(0.63-0.94)$ & 0.011 \\
& $>75$ & 2577 & 433 & $0.90(0.73-1.10)$ & 0.310 \\
& & & & & \\
\hline
\end{tabular}

Extended Data Table 3 | Subgroup analysis stratified by baseline age in US RPDR cohort. 
medRxiv preprint doi: https://doi.org/10.1101/2021.08.10.21261747; this version posted August 12, 2021. The copyright holder for this preprint (which was not certified by peer review) is the author/funder, who has granted medRxiv a license to display the preprint in perpetuity. It is made available under a CC-BY-ND 4.0 International license .

\begin{tabular}{llllll}
\hline Outcome event & $\begin{array}{l}\text { Age categories } \\
\text { (year) }\end{array}$ & \multicolumn{2}{l}{ UK CPRD } & & \\
\cline { 3 - 6 } & $\mathrm{N}$ & Cases & $\mathrm{HR}(95 \% \mathrm{CI})$ & $P$ \\
\hline All-cause & $\leq 65$ & 52570 & 3851 & $0.53(0.43-0.65)$ & $<0.001$ \\
mortality & $>65$ & 55455 & 14263 & $0.72(0.67-0.77)$ & $<0.001$ \\
& $\leq 75$ & 89747 & 11008 & $0.60(0.54-0.67)$ & $<0.001$ \\
& $>75$ & 18278 & 7106 & $0.76(0.71-0.82)$ & $<0.001$ \\
& & & & & \\
Dementia & $\leq 65$ & 52570 & 919 & $0.73(0.51-1.05)$ & 0.091 \\
incidence & $>65$ & 55455 & 6341 & $0.89(0.80-0.99)$ & 0.032 \\
& $\leq 75$ & 89747 & 3876 & $0.83(0.70-0.98)$ & 0.026 \\
& $>75$ & 18278 & 3384 & $0.88(0.78-1.00)$ & 0.048 \\
\hline
\end{tabular}

Extended Data Table 4 | Subgroup analysis stratified by baseline age in the UK CPRD cohort. 


\section{Linear mixed effects model for Hemoglobin A1C repeated measures}

Hemoglobin $A 1 C_{i j}=a+a_{i}+\beta \cdot$ metformin $_{i}+\varepsilon_{i j}$

Number of patients: 10,175

Number of observations: 92,339

\begin{tabular}{|c|c|c|c|}
\hline Parameter & Estimate & Std. Error & t-value \\
\hline Intercept a & 6.967 & 0.02599 & 268.0 \\
\hline Metformin $\beta$ & -0.2056 & 0.02783 & -7.389 \\
\hline
\end{tabular}

\begin{tabular}{|c|c|c|}
\hline Parameter & Variance & Std. Deviation \\
\hline Intercept $\mathrm{a}_{\mathrm{i}}$ & 0.7329 & 0.8561 \\
\hline Metformin $\beta_{\mathrm{ij}}$ & 0.5936 & 0.7705 \\
\hline
\end{tabular}

Extended Data Table 5 | Tabulated results of repeated measures mixed effects model for HbA1C patient data post-baseline, in the US RPDR. Estimates of fixed effects (above) and random effects (below) are provided. Difference in post-baseline HbA1C levels was not clinically significant ( $\mathrm{i}=$ patient; $\mathrm{j}=$ observation). 
medRxiv preprint doi: https://doi.org/10.1101/2021.08.10.21261747; this version posted August 12, 2021. The copyright holder for this preprint (which was not certified by peer review) is the author/funder, who has granted medRxiv a license to display the preprint in perpetuity.

$$
\text { It is made available under a CC-BY-ND } 4.0 \text { International license. }
$$

Extended Data Table 6 | Differential gene expression between drug and DMSO vehicle: metformin 24h and 72h; glyburide 24h and 72h and pathway analysis (Excel file). 


\begin{tabular}{|l|r|}
\hline Human Gene Name & \multicolumn{1}{l|}{ logFC } \\
\hline SPP1 (osteopontin) & -2.34745 \\
\hline BRINP2 & -2.31312 \\
\hline PTGDS (prostaglandin D2 synthetase) & -1.68581 \\
\hline ADAM12 & -1.56585 \\
\hline FAM20C (extracellular serine threonine kinase) & -1.22483 \\
\hline TFRC & -1.16368 \\
\hline CD44 & -1.13569 \\
\hline TF & -1.07581 \\
\hline ANGPTL2 & -0.99027 \\
\hline NOG & 1.064732 \\
\hline SFRP4 & 1.071367 \\
\hline IL16 & 1.114638 \\
\hline MATN2 & 1.166752 \\
\hline GLB1L2 & 1.16997 \\
\hline SLIT1 & 1.202582 \\
\hline MASP1 & 1.239591 \\
\hline COCH & 1.272685 \\
\hline PI16 & 1.277536 \\
\hline VSTM2L & 1.304698 \\
\hline A2ML1 & 1.361365 \\
\hline RELN & 1.409874 \\
\hline CRISPLD2 & 1.464841 \\
\hline TNR (Tenascin) & 1.574132 \\
\hline LDLRAD2 (LDLR Associated D 2) & 1.820836 \\
\hline CILP (Cartilage intermediate layer protein) & 2.070604 \\
\hline VWA5B1 & \\
\hline & \\
\hline
\end{tabular}

Extended Data Table 7 | Genes encoding secreted protein products whose RNA expression levels changed by more than $2 \mathrm{x}$ in response to exposure for 72 hours to $40 \mu \mathrm{M}$ metformin relative to 40 $\boldsymbol{\mu M}$ glyburide in differentiated human ReNcells. Gene names in gray were not detected in CSF proteomic analysis conducted by TMT-LC/MS (1) or Olink methodologies. 
medRxiv preprint doi: https://doi.org/10.1101/2021.08.10.21261747; this version posted August 12, 2021. The copyright holder for this preprint (which was not certified by peer review) is the author/funder, who has granted medRxiv a license to display the preprint in perpetuity. It is made available under a CC-BY-ND 4.0 International license.

Extended Data Table $8 \mid$ US dementia diagnosis codes (Excel File).

Extended Data Table 9 | US dementia/antidiabetic drugs (Excel File).

Extended Data Table 10 | UK dementia diagnosis codes (Excel File).

Extended Data Table 11 | UK dementia/antidiabetic drug codes (Excel File). 